Personal Bankruptcy Law, Debt Portfolios, and Entrepreneurship

Jochen Mankart, Giacomo Rodano

July 2012 Discussion Paper no. 2012-16 


$\begin{array}{ll}\text { Editor: } & \text { Martina Flockerzi } \\ & \text { University of St. Gallen } \\ & \text { School of Economics and Political Science } \\ & \text { Department of Economics } \\ & \text { Varnbüelstrasse 19 } \\ & \text { CH-9000 St. Gallen } \\ & \text { Phone +41 71 224 23 25 } \\ & \text { Fax } \quad+41712243135 \\ & \text { Email seps@unisg.ch } \\ & \text { School of Economics and Political Science } \\ & \text { Department of Economics } \\ & \text { University of St. Gallen } \\ & \text { Varnbüelstrasse 19 } \\ \text { Publisher: } & \text { CH-9000 St. Gallen } \\ & \text { Phone +41 71 224 23 25 } \\ & \text { Fax +41 71 224 31 35 } \\ & \text { http://www.seps.unisg.ch }\end{array}$




\title{
Bankruptcy Law, Debt Portfolios, and Entrepreneurship ${ }^{1}$
}

\author{
Jochen Mankart, Giacomo Rodano
}

Author's address:

Jochen Mankart, $\mathrm{PhD}$

Institute of Economics (FGN-HSG)

Varnbüelstrasse 19

$\mathrm{CH}-9000$ St. Gallen

Phone +41712242155

Fax $\quad+41712242874$

Email_jochen.mankart@unisg.ch

Website www.mankart.net

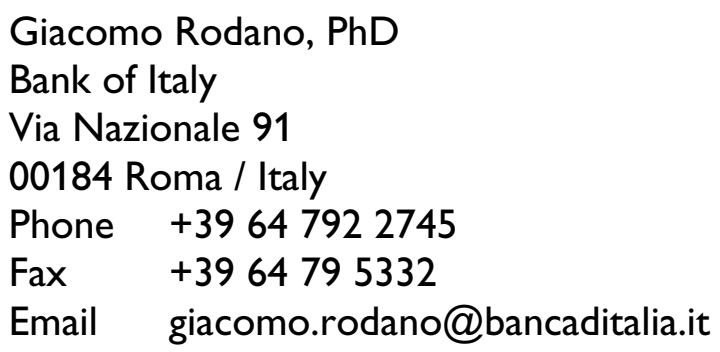

\footnotetext{
${ }^{1}$ We thank Alex Michaelides for his continuous support and valuable comments, and Francesco Caselli and Maitreesh Ghatak for helpful comments at various stages of this research. We are also grateful to Orazio Attanasio, Daniel Becker, Chris Caroll, Wouter Den Haan, Eric Hurst, Bernardo Guimaraes, Christian Julliard, Winfried Koeniger, Tom Krebs, Dirk Krueger, Rachel Ngai, Vincenzo Quadrini, Victor Rios-Rull, Alwyn Young, and participants at the Fifth European Workshop in Macroeconomics, the Heterogeneous Agent Models in Macroeconomics workshop in Mannheim, and the NBER Summer Institute. We thank Dementrio Condello, Roberto Stok, and Nick Warner for their help with computational infrastructure. The views expressed are those of the authors and do not necessarily reflect those of the Bank of Italy. Financial support of the Profilbereich Wirtschaftspolitik at the University of St. Gallen is gratefully acknowledged.
} 


\begin{abstract}
Every year 400,000 entrepreneurs fail and 60,000 file for personal bankruptcy. The option to declare bankruptcy provides entrepreneurs with insurance against the financial consequences of business failures. However, it comes at the cost of worsened credit market conditions. In this paper, we construct a quantitative general equilibrium model of entrepreneurship to show that the presence of secured credit in addition to unsecured credit substantially alters the trade-off between insurance and credit conditions. A lenient bankruptcy law always worsens credit conditions, in particular for poor entrepreneurs. If secured credit is not available, their credit conditions are so bad that many prefer to become workers. In that case, we show that the optimal bankruptcy law is very harsh because the benefits from better credit conditions dominate the worsened insurance. However, if secured credit is available, entrepreneurs who might be rationed out of the unsecured credit market can still obtain secured credit. Therefore, they can run larger firms, which makes entrepreneurship more attractive. Since the presence of secured credit lowers the cost of a generous bankruptcy law, we find that the optimal law is lenient in this case: moving to the optimal bankruptcy law would increase entrepreneurship by more than four per cent.
\end{abstract}

\title{
Keywords
}

Debt portfolio, Bankruptcy, Occupational Choice

\section{JEL Classification}

$\mathrm{M} 13, \mathrm{~K} 10, \mathrm{O} 41, \mathrm{E} 20$ 


\section{Introduction}

In recent years, many countries have changed their personal bankruptcy laws. In Europe, where the bankruptcy law is much harsher than in the U.S., many countries, for example Germany, the Netherlands, and the UK, have made the bankruptcy law more lenient with the explicit aim of fostering entrepreneurship. The U.S. moved in the opposite direction. The "Bankruptcy Abuse Prevention and Consumer Protection Act" of 2005 made it more costly to declare bankruptcy. We contribute to the debate that has led to these legal changes by examining the role of the personal bankruptcy law for entrepreneurs and its macroeconomic implications. Personal bankruptcy law affects entrepreneurs because if an entrepreneur's firm is not incorporated, the entrepreneur is personally liable for all the unsecured debts of the firm. However, despite the fact that entrepreneurs can default on unsecured debt, they overwhelmingly borrow secured.

In this paper we investigate how the possibility of obtaining secured credit in addition to unsecured credit modifies the quantitative effects of the personal bankruptcy law on entrepreneurship. The possibility of filing for bankruptcy introduces some contingency in a world of incomplete credit markets where only simple debt contracts are available. This contingency provides insurance against entrepreneurial failure at the cost of worsening credit conditions. If the bankruptcy law is very generous to defaulters, borrowers are insured against bad outcomes. But in order to compensate for the default risk, banks have to charge high interest rates or ration credit altogether. Allowing for secured credit modifies this trade-off between insurance and credit conditions by allowing agents to obtain cheap credit even under a very generous bankruptcy law. Poor agents are rationed out of the unsecured credit market, independently of the availability of secured credit. But if secured credit is not allowed, these agents will have to self-finance, and therefore will have only very small firms. In contrast, if secured credit is available, these agents can obtain secured credit and therefore are able to have bigger firms. Thus, secured credit weakens the negative effect of a generous bankruptcy law.

To quantify the trade-off in the presence of secured credit, we build an infinite horizon heterogeneous agents model with occupational choice. Each period, an agent decides whether to become an entrepreneur or a worker. An entrepreneur can obtain both secured and unsecured credit. As in Kiyotaki \& Moore (1997), an entrepreneur can borrow secured by pledging their future output and the capital of their firm as collateral. Credit is provided by perfectly competitive financial intermediaries. Conditions for unsecured credit reflect the risk profile of each individual entrepreneur. After uncertainty in production has realized each entrepreneur can decide whether to file for bankruptcy. The bankruptcy law is modeled on U.S. Chapter 7: debt is immediately discharged and after repaying secured debt, all assets in excess of 
an exemption level are liquidated. The proceeds are used to (partially) repay the unsecured creditors.

Our calibrated model replicates important macroeconomic facts - the fraction of entrepreneurs, their exit rate and bankruptcy filings, and the wealth distribution - of the U.S. economy. We use our model to quantify the effects of changing the wealth exemption level. Our main result is that the current personal bankruptcy law is too harsh. There are significant welfare gains from increasing the current exemption level to the optimal one: entrepreneurship would increase from $7.3 \%$ of the population to $7.6 \%$. This is due to the increased insurance effect, which mainly works through a fresh start effect: if the exemption level is high, entrepreneurs who have defaulted can keep a significant amount of wealth which enables them to start another entrepreneurial project soon afterwards. Thus, they enjoy a fresh start. In addition, we show that the optimal exemption level is only slightly lower when we include the transition period in our welfare calculations.

Our results are strikingly different from the other papers in the literature, which find that the current system is too generous. The main reason for this difference is that none of these papers includes secured credit. In a counterfactual experiment, we find that if we had excluded secured credit, we would have obtained similar results as in the previous literature: the current law would appear to be too lenient and exemptions should be lowered. As explained before, ignoring secured credit overestimates the cost of a generous bankruptcy law and therefore biases the welfare calculations. Another way of understanding this is the following. If secured credit is not taken into account, the optimal policy is a harsh bankruptcy law, because most agents do not value the insurance benefit provided by the bankruptcy law as much as they value better credit conditions. These agents want a commitment device that takes away the default option. If secured credit is not part of the model, a harsher bankruptcy law is the only way of achieving this. But secured credit, if it is available, is another commitment device that the agents can and do use. In the model, and in the data, more than $90 \%$ of entrepreneurial borrowing is secured.

The costs of a generous bankruptcy system, in terms of higher interest rates, depend mainly on the elasticity of intertemporal substitution, while the benefits, in terms of insurance, depend on risk aversion. In contrast to the previous literature, we examine these effects separately by assuming Epstein-Zin preferences. We find that the optimal exemption level increases with the elasticity of intertemporal substitution. This result is intuitive, since agents who are more willing to substitute consumption across time are less affected by the higher borrowing rates resulting from higher exemption levels. We also find that the optimal exemption level increases with risk aversion. The more risk averse are the agents, the more they value insurance. The optimal exemption level is high for all values of the preference parameters, showing the 
robustness of our main result to changes in preferences.

Our paper is part of the quantitative literature on entrepreneurship and personal bankruptcy. $\left.\right|^{1}$ Akyol \& Athreya (2011) use a life cycle model which includes human capital to also investigate the optimal exemption level. Meh \& Terajima (2008) study the same question when also consumers can default. In contrast to us, both papers find that the current system is too generous. Our results, as also the results in these two papers are consistent with the empirical finding of Berkowitz \& White (2004), who show that in states with higher exemption levels, credit conditions are worse. But our paper is the only one that is also consistent with the findings of Fan \& White (2003), who show that entrepreneurship is higher in states with a more lenient bankruptcy law. Jia (2010) compares the U.S. bankruptcy regime with European ones and finds that the more lenient system in the U.S. encourages entrepreneurship. All these papers use partial equilibrium models. We use a general equilibrium model and also study the transitional dynamics.

Glover \& Short (2011) and Herranz, et al. (2008) innovate by allowing entrepreneurs to incorporate their firms, thereby shielding their private assets from a business failure. However, since a significant fraction of entrepreneurs use private assets to obtain credit, so that the distinction between incorporated and non-incorporated firms is not that clear (Fan \& White, 2003), we abstract from this interesting issue. Moreover, Glover \& Short (2011) abstract from differences in labor productivity which are important because the outside option of entrepreneurship is paid work. Herranz et al. (2008) abstract from occupational choice altogether.

Most importantly, and as already mentioned, none of these papers includes secured credit in addition to unsecured credit, and this inclusion is the key element of our analysis.

The present paper is organized as follows. Section 2 provides an overview of U.S. bankruptcy law and presents the data on entrepreneurial failure. Section 3 includes our model and discusses the equilibrium conditions. Section 4 explains the main mechanism of the model and presents the results of our main policy experiment. Section 5 concludes. The Appendix includes our computational strategy and describes our data in more detail.

\footnotetext{
${ }^{1}$ Our paper is related to the broader quantitative literature of entrepreneurship in models of occupational choice, as for example Quadrini (2000), Cagetti \& De Nardi (2006), and Vereshchagina \& Hopenhayn (2009). However, all these papers abstract from risky debt and default which are central to our model. Our paper is also related to the quantitative models on consumer bankruptcy. However, most papers in this literature, see for example Livshits, et al. (2007) and Chatterjee, et al. (2007), also ignore secured credit. Athreya (2006), Hintermaier \& Koeniger (2011), and Pavan (2008) include secured and unsecured credit. In particular, the first of these also finds that the optimal exemption level in this case is very high.
} 


\section{Personal bankruptcy and entrepreneurial failure in the U.S.}

Personal Bankruptcy. Personal bankruptcy law in the U.S. consists of two different procedures: Chapter 7 and Chapter 13. Under Chapter 7, all unsecured debt is discharged immediately, while a secured creditor can fully seize the assets pledged as collateral. Future earnings cannot be garnished. This is why Chapter 7 is known as providing a fresh start. At the same time, a person filing for bankruptcy has to surrender all wealth in excess of an exemption level. Under Chapter 13 agents can keep their wealth, debt is not discharged immediately, and future earnings are garnished. Entrepreneurs are better off under Chapter 7 for three reasons: they have no non-exempt wealth, their debt is discharged immediately, and they can start a new business right away, since their income will not be subject to garnishment (see White, 2007). Indeed $70 \%$ of total bankruptcy cases involving entrepreneurs are under Chapter 7 . Therefore we will focus on Chapter 7 only.

The main parameter in the model representing the Chapter 7 procedure is the exemption level, $2^{2}$ which varies across U.S. states, ranging from $\$ 11,000$ in Maryland to an unlimited exemption for housing wealth in some states, for example Florida. To calibrate this parameter, we calculate the population-weighted median across states. The resulting exemption level is $\$ 47,800$ in $1993 !^{3}$

A person can file for bankruptcy only once every six years. The bankruptcy filing remains public information for ten years. Therefore, while secured (i.e., collateralized) credit is always available, agents might have difficulties obtaining unsecured credit for some time after having defaulted. In the model we capture this possibility by assuming that defaulting entrepreneurs are excluded from unsecured credit for six years.

Entrepreneurial failure. The U.S. Small Business Administration reports that according to the official data from the Administrative Office of the Courts for the period 1990-2005, on average about $1 \%$ of all entrepreneurs file for bankruptcy each year. 4 Unfortunately, the official data on personal bankruptcy caused by a business failure seem to be severely downward biased.

\footnotetext{
${ }^{2}$ Since our data are from before 2005, we model Chapter 7 as it was prior to the changes made by the "Bankruptcy Abuse Prevention and Consumer Protection Act".

${ }^{3}$ The wealth exemption level does not change much over time. We chose 1993 because it is in the middle of the sample years for our data on entrepreneurship wealth distribution and bankruptcies.

${ }^{4}$ The U.S. Small Business Administration divides small firms into employer (i.e., with at least one employee) and non-employer firms. Since in the present paper we focus on entrepreneurs who own and manage the firm, we use only the data for employer firms. To ensure consistency between our three databases, when we use data from the Survey of Consumer Finance (SCF) and the Panel Study of Income Dynamics (PSID), we define entrepreneurs as business owners who manage a firm with at least one employee. See the data appendix for more details.
} 
Lawless \& Warren (2005) estimate that the true number could be three to four times as large. Their own study is based on an in-depth analysis of bankruptcy filers in five different judicial districts. Their explanation of this discrepancy is the emergence of automated classification of personal bankruptcy cases. Almost all software used in this area has "consumer case" as the default option. Thus reporting a personal bankruptcy case as a "business related" case requires some - even though small - effort, while being completely inconsequential for the court proceedings. In addition to their own study, they report data from Dun \& Bradstreet according to which business bankruptcies are at least twice the official number.5 $5^{5}$ In the baseline calibration, therefore, we set the default rate of entrepreneurs to $2.25 \%$.

\section{The model}

Our economy is populated by a unit mass of infinitely lived heterogeneous agents. At the beginning of every period, agents decide whether to become workers or entrepreneurs. An entrepreneur must decide how much to invest, how much to borrow secured and, if allowed to, how much to borrow unsecured. An entrepreneur who has defaulted on unsecured credit is excluded from unsecured credit for six years but is allowed to obtain secured credit. Since we focus on the implications of personal bankruptcy for entrepreneurs, workers are not allowed to borrow ${ }^{6}$

Agents face idiosyncratic uncertainty, but there is no aggregate uncertainty. Agents' productivities evolve over time and entrepreneurs are subject to uninsurable production risk. After the shocks are realized, production takes place. At the end of the period, unsecured borrowers decide whether to repay or default and how much to consume and save. Anticipating entrepreneurs' behavior, banks set the interest rate for each unsecured loan taking into account the individual borrower's default probability. The remainder of this section presents the details of the model.

\footnotetext{
${ }^{5}$ Dun \& Bradstreet (D\&B) is a credit reporting and business information firm that compiles its own independent business failure database. Until the emergence of automated software for law firms and courts in the mid 1980s, the official business bankruptcy data and the index compiled by D\&B had a positive and significant correlation of 0.73. From 1986-1998, this correlation coefficient becomes negative and insignificant. Extrapolating from the historic relationship between the D\&B index and personal bankruptcy cases caused by business failures leads to the conclusion that the official data under report business bankruptcy cases at least by a factor of two.

${ }^{6}$ Thus, our welfare results translate into policy advice only if the bankruptcy law distinguishes between business related personal bankruptcy and consumer bankruptcy.
} 


\subsection{Credit and bankruptcy law}

Agents can get two types of credit: secured and unsecured. Both types of credit are subject to a limited commitment problem. $]^{7}$ After obtaining credit, all borrowers have two options: either start the entrepreneurial activity, or run away with a fraction $\lambda$ of their liquid assets (that is, their own wealth plus the amount borrowed). If the agents start the entrepreneurial activity, the difference between the two kinds of credit is that secured credit must be repaid, while unsecured credit is subject to Chapter 7 bankruptcy procedure if the agent exercises their default option. In the event of a default, therefore, the agent still must repay their secured debt, while their unsecured debt is discharged. After repaying the secured debt, any assets in excess of the exemption level $X$ are liquidated and the proceeds are collected by the creditors.

An agent who has defaulted in the past is excluded from the market for unsecured credit for a certain period of time, during which secured credit can still be obtained and the agent can thus become an entrepreneur. We call such an agent borrowing constrained and we denote such a credit status as $B C$. To avoid an additional discrete state variable, we model the exclusion period in a probabilistic way ${ }^{8}$ At the end of the period, every borrowing constrained agent, whether worker or entrepreneur, faces a credit status shock. With probability $(1-\varrho)$, that agent remains borrowing constrained. With probability $\varrho$, the agent regain access to unsecured credit and becomes an unconstrained agent, with credit status $U N$.

\section{$3.2 \quad$ Households}

Our economy is populated by a unit mass of infinitely lived heterogeneous agents. Agents differ in their level of assets $a$, their entrepreneurial productivity $\theta$, their working productivity $\varphi$, and their credit market status $S \in\{U N, B C\}$.

Preferences. For simplicity, we abstract from the labor-leisure choice. All agents supply their unit of labor inelastically, either as workers or as entrepreneurs. In order to disentangle the effects of risk aversion from that of the elasticity of inetertemporal substitution, we assume that agents have Epstein-Zin preferences. A stochastic consumption stream $\left\{c_{t}\right\}_{t=0}^{\infty}$ generates a utility $\left\{u_{t}\right\}_{t=0}^{\infty}$ according to

$$
u_{t}=U\left(c_{t}\right)+\beta U\left(\mathbb{C E}_{t}\left[U^{-1}\left(u_{t+1}\right)\right]\right),
$$

where $\beta$ is the discount rate and $\mathbb{C E}_{t}\left[U^{-1}\left(u_{t+1}\right)\right] \equiv \Gamma^{-1}\left[\mathbb{E}_{t} \Gamma\left(u_{t+1}\right)\right]$ is the consumption equivalent of $u_{t+1}$ given information at period $t$. The utility function $U(c)=c^{1-\frac{1}{\psi}} /\left(1-\frac{1}{\psi}\right)$ aggre-

\footnotetext{
${ }^{7}$ We introduce this limited commitment problem to obtain reasonable leverage ratios. As shown by Heaton \& Lucas (2002), models without information asymmetries yield unrealistically large leverage ratios.

${ }^{8}$ This procedure is standard in the literature, see Athreya $(2002)$ and Chatterjee et al. (2007).
} 
gates utility over time and $\psi$ is the intertemporal elasticity of substitution. The utility function $\Gamma(c)=c^{1-\gamma} /(1-\gamma)$ aggregates utility across states and $\gamma$ is the coefficient of relative risk aversion.

Productivities. Each agent is endowed with two stochastic productivity levels which are known at the beginning of the period: one as an entrepreneur $\theta$, and one as a worker $\varphi$. We make the simplifying assumption that the working and entrepreneurial ability processes are uncorrelated.

Following the literature, we assume that labor productivity follows the AR(1) process

$$
\log \varphi_{t}=(1-\rho) \mu+\rho \log \varphi_{t-1}+\varepsilon_{t}
$$

where $\varepsilon_{t}$ is $i i d$ and $\varepsilon \sim N\left(0, \sigma_{\varepsilon}\right)$. The labor income of an agent becoming a worker during the current period is given by $w \varphi$.

In contrast to the case of working ability, there are no reliable estimates of the functional form for the case of entrepreneurial ability. Therefore, following Cagetti \& De Nardi (2006), we assume a parsimonious specification in which entrepreneurial productivity follows a 2-state Markov process with $\theta^{L}=0$ and $\theta^{H}>0$ and transition matrix

$$
P_{\theta}=\left[\begin{array}{cc}
p^{L L} & 1-p^{L L} \\
1-p^{H H} & p^{H H}
\end{array}\right]
$$

in which there are three parameters, $\theta^{H}, p^{H H}$, and $p^{L L}$, which are to be calibrated.

\subsection{Technology}

The entrepreneurial sector. Each agent in the economy has access to a productive technology that, depending on that agent's particular entrepreneurial productivity $\theta$, produces output according to the production function

$$
\begin{aligned}
Y & =\theta k^{\nu} \\
k & =\chi I
\end{aligned}
$$

where $\theta$ is the agent's persistent entrepreneurial productivity described above.

We assume that investment is subject to an iid idiosyncratic shock. Each unit of the numeraire good which is invested in the entrepreneurial activity is transformed into $\chi$ units of capital, with $\log \chi \sim N\left(0, \sigma_{\chi}\right)$. This iid shock represents the possibility that an inherently talented entrepreneur (i.e., an agent with a high and persistent $\theta$ ) might choose the wrong 
project or could be hit by an adverse demand shock. Quadrini (2000) shows that the entry rate of workers with some entrepreneurial experience in the past is much higher than the entry rate of those workers without any experience. Therefore, it seems that entrepreneurs come mostly from a small subset of the total population. If their firms fail, they are very likely to start a new firm within a few years.

Corporate sector. Many firms are both incorporated and big enough not to be subject to personal bankruptcy law. Therefore we follow Quadrini (2000) and Cagetti \& De Nardi (2006) and assume a perfectly competitive corporate sector which is modeled as a Cobb-Douglas production function

$$
F\left(K_{c}, L_{c}\right)=A K_{c}^{\xi} L_{c}^{1-\xi},
$$

where $K_{c}$ and $L_{c}$ are the capital and labor employed in this sector. Given perfect competition and constant returns to scale, the corporate sector does not generate any profits. Capital depreciates at the rate $\delta$ in both sectors.

\subsection{Credit market}

We assume that there is perfect competition and free entry to the credit market. Therefore, banks must make zero expected profits on any contract. The opportunity cost of lending to entrepreneurs is the rate of return on capital in the corporate sector. This is also equal to the deposit rate.$^{9}$ Agents can get two types of credit: secured and unsecured. Secured credit represents collateralized borrowing. Thus, it is available at the risk free rate plus a small transaction cost $\left(r^{s}=r^{d}+\tau^{s}\right)$. If the agent saves, secured credit is negative and $\left(r^{s}=r^{d}\right)$. Unsecured credit incurs higher transaction costs $\left(\tau^{u}>\tau^{s}\right)$, which reflect the higher costs of information acquisition. Both types of contracts are subject to the limited commitment constraint, and banks will never lend an amount so large that the agent would then certainly prefer to run.

There are no information asymmetries in the credit market: banks know the agent's assets, the amount that has been borrowed secured, and the agent's productivity. For any given value of $(a, s, \theta, \varphi)$ and for any amount of unsecured credit $b$, banks are able to calculate the probability of default and the recovery rate in case of default by anticipating the behavior of the entrepreneur. Perfect competition implies that they set the interest rate, $r(a, s, \theta, \varphi, b)$, so that they expect to break even. This interest rate depends on the exemption level $X$ because it affects the incentives to default and the amount the bank recovers in this event. Therefore,

\footnotetext{
${ }^{9}$ In our model, banks are equivalent to a bond market in which each agent has the possibility of issuing debt.
} 
banks offer a menu of one period debt contracts which consist of an amount lent $b$ and a corresponding interest rate $r(a, s, \theta, \varphi, b)$ to each agent with characteristics $(a, s, \theta, \varphi)$.

\subsection{Timing}

Figure 1 shows the timing of the model. Entrepreneurs' borrowing and default decisions are taken within the period. At the beginning of the period, all agents face the occupational choice of whether to become entrepreneurs or workers. Agents know their current productivities $(\varphi, \theta)$.

Workers deposit all their wealth at the banks, receiving a rate of return $r^{d}$. After production has taken place, they choose consumption and savings. At the end of the period, the borrowing constrained worker receives a credit status shock. With probability $\varrho$, the worker remains borrowing constrained in the next period (i.e., $S^{\prime}=B C$ ). With probability $(1-\varrho)$, the worker becomes unconstrained in the next period (i.e., $S^{\prime}=U N$ ).

The borrowing constrained entrepreneur chooses how much secured credit or whether to save and then decides whether to engage in production or run away with the liquid assets. All these decisions are taken before the iid shock $\chi$ is realized. After $\chi$ is realized and production has taken place, the entrepreneur chooses consumption and savings and at the end of the period receives the credit status shock.

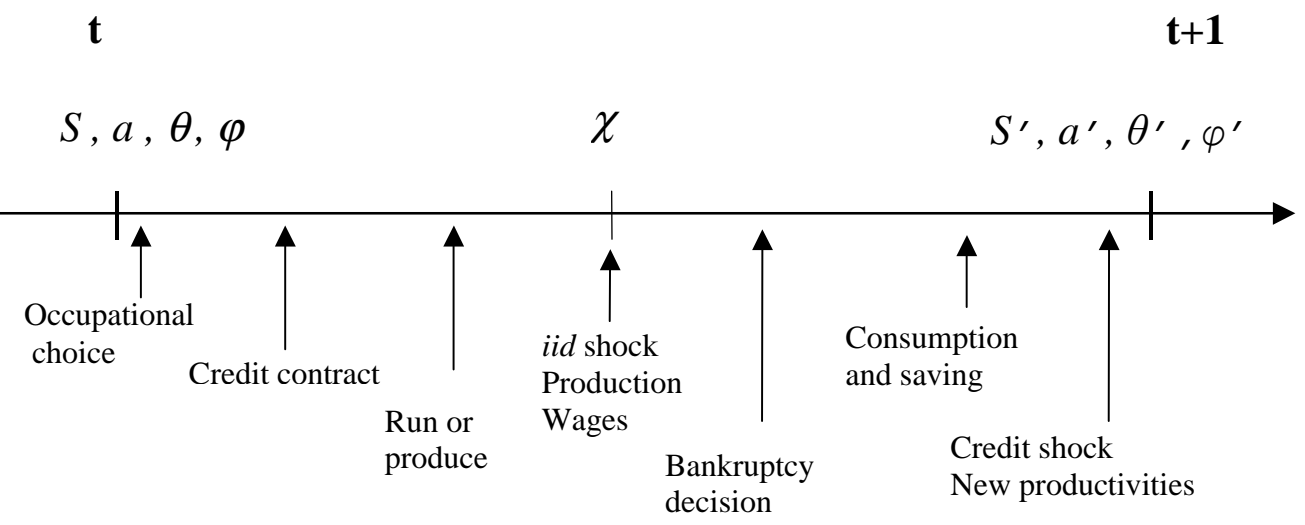

Figure 1: Timing of the model

The unconstrained entrepreneur can obtain secured credit $s$ and unsecured credit $b$, and chooses capital stock before knowing $\chi$, by deciding how much to borrow (or invest at rate $\left.r^{d}\right)$. Secured credit $s$ can be obtained at the interest rate $r^{s}$ and unsecured borrowing is done by choosing from the menu $\{b, r(a, \theta, \varphi, s, b)\}$ offered by the the banks. Similarly to the borrowing constrained entrepreneur, the unconstrained entrepreneur can take $a+b+s$ and run. 
And as before, banks will never lend an amount so large that the agent would then certainly prefer to run. After $\chi$ is realized and production has taken place, the entrepreneur must first repay the secured debt and then decide whether to repay the unsecured debt as well and be unconstrained in the next period (i.e., $S^{\prime}=U N$ ) or whether to declare bankruptcy and be borrowing constrained for the next period (i.e., $S^{\prime}=B C$ ). The choice of consumption and savings then comes after that.

Since the credit status $S$ can take one of only two states $B C$ and $U N$, we define the individual state variable to be $(a, \theta, \varphi)$, and solve for the two value functions $V^{U N}(a, \theta, \varphi)$ and $V^{B C}(a, \theta, \varphi)$, one for each credit status.

\subsection{The problem of the borrowing constrained agent}

The borrowing constrained agent can only obtain secured credit subject to the limited commitment constraint. At the beginning of the period such an agent can choose whether to become an entrepreneur, which yields utility $N^{B C}(a, \theta, \varphi)$, or a worker, which yields utility $W^{B C}(a, \theta, \varphi)$. Therefore the value of being a borrowing constrained agent with state $(a, \theta, \varphi)$ is

$$
V^{B C}(a, \theta, \varphi)=\max \left\{N^{B C}(a, \theta, \varphi), W^{B C}(a, \theta, \varphi)\right\},
$$

where the "max" operator reflects the occupational choice.

Workers. At the beginning of the period borrowing constrained workers deposit all their wealth at the bank and receive labor income $w \varphi$. Consumption and saving is chosen at the end of the period, taking into account the future reception of a credit status shock in addition to productivity shocks. With probability $\varrho$ such a worker will still be borrowing constrained in the next period, which yields utility $V^{B C}\left(a^{\prime}, \theta^{\prime}, \varphi^{\prime}\right)$, while the probability of becoming unconstrained is $(1-\varrho)$, which yields utility $V^{U N}\left(a^{\prime}, \theta^{\prime}, \varphi^{\prime}\right)$. The saving problem is, then, the following ${ }^{10}$

$$
\begin{aligned}
W^{B C}(a, \theta, \varphi) & =\max _{c, a^{\prime}}\left\{U(c)+\beta U\left(\mathbb{C E}\left[\varrho V^{B C}\left(a^{\prime}, \theta^{\prime}, \varphi^{\prime}\right)+(1-\varrho) V^{U N}\left(a^{\prime}, \theta^{\prime}, \varphi^{\prime}\right)\right]\right)\right\} \\
\text { s.t. } c+a^{\prime} & =w \varphi+\left(1+r^{d}\right) a \\
a^{\prime} & \geq 0
\end{aligned}
$$

Entrepreneurs. At the beginning of the period, the borrowing constrained entrepreneur decides how much to borrow secured, and so, how much to invest in their firm $I=a+s$. Each

\footnotetext{
${ }^{10}$ As discussed at the beginning of this section, our paper focuses on the role of Chapter 7 for entrepreneurs. Therefore, we do not allow agents to have negative assets across periods. Otherwise, it would become possible for a worker to accumulate debt and then become an entrepreneur only in order to obtain the possibility of defaulting.
} 
unit of investment is transformed into $k=\chi I$ units of capital. The entrepreneur could take the money and run away with the fraction $\lambda$. If so, the utility is then given by ${ }^{11}$

$$
\begin{aligned}
\Upsilon[I, \theta, \varphi] & =\max _{c, a^{\prime}}\left\{U(c)+\beta U\left(\mathbb{C E}\left[V^{B C}\left(a^{\prime}, \theta^{\prime}, \varphi^{\prime}\right)\right]\right)\right\} \\
\text { s.t. } c+a^{\prime} & =\lambda I \\
a^{\prime} & \geq 0 .
\end{aligned}
$$

After the shock $\chi$ is realized, the decision how to allocate the resources among consumption and savings will be made, and the consequent saving problem, after uncertainty is resolved, ${ }^{12}$ is

$$
\begin{aligned}
\tilde{N}^{B C}(a, \theta, \varphi, \chi, s) & =\max _{a^{\prime}, c}\left\{U(c)+\beta U\left(\mathbb{C E}\left[\varrho V^{B C}\left(a^{\prime}, \theta^{\prime}, \varphi^{\prime}\right)+(1-\varrho) V^{U N}\left(a^{\prime}, \theta^{\prime}, \varphi^{\prime}\right)\right]\right)\right\} \\
\text { s.t. } c+a^{\prime} & =[\chi(a+s)]^{\nu} \theta+(1-\delta) \chi(a+s)-\left(1+r^{s}\right) s \\
a^{\prime} & \geq 0 .
\end{aligned}
$$

Therefore the optimal investment decision of the agent at the beginning of the period is

$$
\begin{aligned}
N^{B C}(a, \theta, \varphi) & =\max _{s}\left\{U\left(\mathbb{C E}\left[\tilde{N}^{B C}\left(a, \theta^{\prime}, \varphi^{\prime}, \chi, s\right)\right]\right)\right\} \\
\text { s.t. } N^{B C}(a, \theta, \varphi) & \geq \Upsilon[a+s, \theta, \varphi],
\end{aligned}
$$

where the constraint is imposed by the banks. As discussed before, they would never offer a credit contract that violates the incentive compatibility constraint.

\subsection{The problem of the unconstrained agent}

At the beginning of the period, the unconstrained agent faces the occupational choice

$$
V^{U N}(a, \theta, \varphi)=\max \left\{W^{U N}(a, \theta, \varphi), N^{U N}(a, \theta, \varphi)\right\}
$$

where $W^{U N}(a, \theta, \varphi)$ is the utility of becoming a worker and $N^{U N}(a, \theta, \varphi)$, that of becoming an entrepreneur.

Workers. The problem of the unconstrained worker is identical to the borrowing constrained one, except that the agent will be unconstrained in the future for sure. The saving problem is then

\footnotetext{
${ }^{11}$ This outside option is available to the unconstrained entrepreneur as well.

${ }^{12} \mathrm{~A}$ value function superscribed by a tilde denotes that function after the uncertainty about $\chi$ is resolved. The value functions without a tilde are those before the uncertainty is resolved.
} 


$$
\begin{aligned}
W^{U N}(a, \theta, \varphi) & =\max _{c, a^{\prime}}\left\{U(c)+\beta U\left(\mathbb{C E}_{t}\left[V^{U N}\left(a^{\prime}, \theta^{\prime}, \varphi^{\prime}\right)\right]\right)\right\} \\
\text { s.t. } c+a^{\prime} & =w \varphi+\left(1+r^{d}\right) a \\
a^{\prime} & \geq 0 .
\end{aligned}
$$

Entrepreneurs. The unconstrained entrepreneur decides how much to invest, $I=a+b+s$, by choosing how much to borrow secured (or how much to save) and how much to borrow unsecured. If borrowing unsecured credit, the menu $\{b, r(a, \theta, \varphi, b, s)\}$ is offered by competitive banks. After the shock $\chi$ is realized, the choice is between whether to declare bankruptcy (default) or whether to repay, and how much to consume and save. This problem is solved backwards. If repaying the unsecured debt, the choice is how to allocate resources between consumption and savings. Given that the decision of repaying is taken when current productivities $(\theta, \varphi)$ and the shock $\chi$ are known, the utility from repaying is

$$
\begin{aligned}
\tilde{N}^{p a y}(a, b, s, \theta, \varphi, \chi)= & \max _{c, a^{\prime}}\left\{U(c)+\beta U\left(\mathbb{C E}\left[V^{U N}\left(a^{\prime}, \theta^{\prime}, \varphi^{\prime}\right)\right]\right)\right\} \\
\text { s.t. } a^{\prime}+c= & \theta[(a+b+s) \chi]^{\nu}+(1-\delta)(a+b+s) \chi-\cdots \\
& -b[1+r(a, \theta, \varphi, b, s, X)]-\left(1+r^{s}\right) s \\
a^{\prime} \geq & 0
\end{aligned}
$$

If defaulting, the unsecured debt is discharged, but the secured debt must be repaid and all assets in excess of the exemption level $X$ are lost. Moreover, if defaulting, the agent's credit status will change to $\left(S^{\prime}=B C\right)$, and any borrowing in the next period will be secured borrowing only. Therefore by declaring bankruptcy,

$$
\begin{aligned}
\tilde{N}^{\text {bankr }}(a, b, s, \theta, \varphi, \chi) & =\max _{c, a^{\prime}}\left\{U(c)+\beta U\left(\mathbb{C E}\left[V^{B C}\left(a^{\prime}, \theta^{\prime}, \varphi^{\prime}\right)\right]\right)\right\} \\
\text { s.t. } a^{\prime}+c & =\min \left\{\theta[(a+b+s) \chi]^{\nu}+(1-\delta)(a+b+s) \chi-\left(1+r^{s}\right) s, X\right\} \\
a^{\prime} & \geq 0
\end{aligned}
$$

is received.

Bankruptcy will be declared if $N^{b a n k r}(a, b, s, \theta, \varphi \chi)>N^{p a y}(a, b, s, \theta, \varphi, \chi)$, and vice versa. Thus, at the beginning of the period, the agents choose the optimal amount of $b$ from the menu $\{b, r(a, \theta, \varphi, b)\}$ and the optimal $s$ anticipating their future behavior. Therefore their utilities are given by

$$
\begin{aligned}
N^{U N}(a, \theta, \varphi) & =\max _{b, s}\left\{U\left(\mathbb{C E}\left[\max \left\{\tilde{N}^{\text {pay }}(a, b, s, \theta, \varphi, \chi), \tilde{N}^{\text {bankr }}(a, b, s, \theta, \varphi, \chi)\right\}\right]\right)\right\} \\
\text { s.t. } N^{U N}(a, \theta, \varphi) & \geq \Upsilon[a+s+b, \theta, \varphi]
\end{aligned}
$$


where the "max" operator inside the square brackets reflects the bankruptcy decision, and the "max" operator outside the square brackets reflects the borrowing decision. The last equation represents the limited commitment constraint.

\subsection{The zero profit condition of the banks}

Banks observe the state variables $(a, \theta, \varphi)$ at the moment of offering the contract. There is perfect competition (free entry) in the credit market, and therefore the banks make zero profit on each secured and unsecured loan contract. The bank is, therefore, indifferent between issuing secured and unsecured loans. For each unit of secured credit, the bank knows that the agent will repay for sure: free entry will push the interest rate on secured credit to the risk free rate plus the transaction cost $\tau^{s}$. For any given state $(a, \theta, \varphi)$ and for any given amount of secured borrowing $s$ and for any unsecured loan $b$, the bank knows in which states of the world the agent will file for bankruptcy. Therefore, it is able to calculate the probability that a certain agent with characteristics $(a, \theta, \varphi)$, and secured loan $s$, will default for any given amount $b$. This default probability, $\pi(a, \theta, \varphi, b, s)$, depends on the exemption level $X$, since this directly affects the incentive to default.

If the agent repays, the bank receives the outstanding repayment. If the agent defaults, the bank obtains all assets in excess of the exemption level. If these assets are below the exemption level, the bank obtains nothing. Thus, the zero profit condition of the banks is

$$
\left(\begin{array}{c}
{[1-\pi(a, \theta, \varphi, b, s)][1+r(a, \theta, \varphi, b, s)] b+} \\
+\pi(a, \theta, \varphi, b, s) \\
\max \left\{\theta[\chi I]^{\nu}+(1-\delta) \chi I-\left(1+r^{d}\right) s-X, 0\right\}
\end{array}\right)=\left(1+r^{d}+\tau^{u}\right) b
$$

where $I=a+b+s$

\subsection{Equilibrium}

Suppose $\eta=(a, \theta, \varphi, S)$ is a state vector for an individual, where $a$ denotes the assets, $\theta$ the entrepreneurial productivity, $\varphi$ the working productivity, and $S$ the credit status. From the optimal policy functions (occupational choice, savings, capital demand, and default decisions), from the exogenous Markov process for productivity and from the credit status shocks, we can derive a transition function that, for any distribution $\mu(\eta)$ over the state space, provides the next period distribution $\mu^{\prime}(\eta)$. A stationary equilibrium is then given by

- a deposit rate of return $r^{d}$ and a wage rate $w$;

\footnotetext{
${ }^{13}$ We also assume that banks impose an endogenous borrowing limit that prevents entrepreneurs from signing credit contracts which would imply a default probability of $100 \%$.
} 
- an interest rate function;

- a set of policy functions $g(\eta)$ (consumption and saving, secured and unsecured borrowing, capital demand, bankruptcy decisions, and occupational choice);

- a constant distribution over the state space $\eta, \mu^{*}(\eta)$;

such that, given $r^{d}$ and $w$ and a bankruptcy regime $(X, \varrho)$ :

- $g(\eta)$ solves the maximization problem of the agents;

- the corporate sector representative firm is optimizing;

- capital, labor and goods market clear:

- capital demand comes from both entrepreneurs and the corporate sector, while supply comes from the saving decisions of the agents;

- labor demand comes from the corporate sector, while labor supply comes from the occupational choices of the agents;

- the interest rate function reflects the zero profit condition of the banks;

- the distribution $\mu^{*}(\eta)$ is the invariant distribution associated with the transition function generated by the optimal policy function $g(\eta)$ and the exogenous shocks.

The model has no analytical solution and must be solved numerically. The algorithm used to solve the model is presented in the Appendix.

\section{Results}

\subsection{Parametrization}

Preference parameters. In the baseline model, the coefficient of relative risk aversion $\sigma$ is set to 2 and the elasticity of intertemporal substitution $\psi$ is set to 0.9 .14 Panel A of Table 1 summarizes the preferences parameters.

\footnotetext{
${ }^{14}$ We investigate the robustness of our results to values of $\sigma$ ranging from 3 to 5 and $\psi$ ranging from 0.75 to 1.1 in Section 4.6 below.
} 
Bankruptcy parameters. In the model, the U.S. bankruptcy system is characterized by two parameters: the exemption level $X$ and the probability $\varrho$ of being able to obtain unsecured credit again. Following the discussion in Section 2, we set $X=\$ 47,800$. Given that the average household labor income is $\$ 48,600$, this corresponds to a value of 0.98 for the ratio of exemption to average labor income. Individuals can file for Chapter 7 bankruptcy only once every six years. Therefore, we set $\varrho=1 / 6$. Panel B of Table 1 summarizes the bankruptcy parameters.

Table 1: Fixed parameters

Panel A: Preferences

\begin{tabular}{lcc}
\hline Parameter & Symbol & Value \\
\hline CRRA & $\sigma$ & 2 \\
IES & $\psi$ & 0.9 \\
\hline
\end{tabular}

Panel B: Bankruptcy

\begin{tabular}{lcc}
\hline Parameter & Symbol & Value \\
\hline Exemption/wage & $X / w$ & 0.98 \\
Unsecured credit exclusion (expressed as probability) & $\varrho$ & $1 / 6$ \\
\hline
\end{tabular}

Panel C: Other parameters

\begin{tabular}{lcc}
\hline Parameter & Symbol & Value \\
\hline TFP & $A$ & 1 (normalization) \\
Share of capital & $\xi$ & 0.36 \\
Transaction cost secured credit & $\tau^{s}$ & 0.01 \\
Transaction cost unsecured credit & $\tau^{u}$ & 0.04 \\
Depreciation rate & $\delta$ & 0.08 \\
Earnings: autocorrelation & $\rho$ & 0.95 \\
Earnings: variance of innovation & $\sigma_{\varepsilon}^{2}$ & 0.08125 \\
\hline
\end{tabular}

Other fixed parameters. Following the standard practice in the literature, we try to minimize the number of parameters we match to the data using the model. We therefore select parameter values from estimates in the literature whenever possible. The total factor productivity $A$ is normalized to 1 . The share of capital in the Cobb-Douglas technology for the corporate sector $\xi$ is set to 0.36 . The depreciation rate $\delta$ is set to 0.08 . We choose the auto-regressive 
coefficient of the workers' earnings process $\rho$ to be 0.95 .15 The variance of the innovation in the earnings process is chosen to match the Gini index of labor income as observed in the PSID, which is 0.38. ${ }^{16}$ The process is approximated using a four state Markov chain, using the Tauchen (1986) method as suggested by Adda \& Cooper (2003). The intermediation cost of unsecured credit $\tau^{u}$ is set to $4 \%$. This is based on evidence of credit card borrowing by Evans $\&$ Schmalensee (1999). The intermediation cost of secured credit $\tau^{s}$ is set to $1 \% \cdot 17$ These parameters are summarized in Panel C of Table 1 .

Calibrated parameters. The remaining seven parameters are chosen jointly so that the model matches seven moments of the U.S. economy as to entrepreneurship, default, and the wealth distribution. The discount factor $\beta$ helps to match the capital-output ratio of the U.S. economy, which is 3.1. The persistence of the low entrepreneurial productivity state $p^{L L}$ captures the fraction of entrepreneurs in the total population, which is $7.3 \%$ in the Survey of Consumers Finances ${ }^{18}$ The persistence of the high entrepreneurial productivity state $p^{H H}$ helps to match the exit rate of entrepreneurs, which is equal to $15 \%$ in the PSID. The fraction of cash on hand with which an agent can run away, $\lambda$, helps to match the median leverage ratio of entrepreneurs of $37.4 \% \cdot 19$

The variance of the transitory shock $\sigma_{\chi}$ helps to match the default rate of entrepreneurs. Given the discussion in Section 2, we set this equal to $0.164 \%$ of the total population. The high value of entrepreneurial productivity $\theta^{H}$ and the concavity of the entrepreneurial production function $\nu$ are important for matching some characteristics of the wealth distribution, since the benefits of bankruptcy depend crucially on the wealth of the agent. The U.S. wealth distribution is extremely skewed: we match the share of total wealth held by the $40 \%$ richest households, which is about $94 \%$. Moreover, entrepreneurs are significantly richer than workers: we match the ratio of the median wealth of entrepreneurs to the median wealth in the whole population, which is 6.3 in the SCF. Table 2 gives the values of the calibrated parameters in the baseline specification of the model. The targets are summarized in the third column of Table 3 .

\footnotetext{
${ }^{15}$ In a life cycle setting, Storesletten, et al. (2004) and Storesletten, et al. (2001) find $\rho$ to be between 0.95 and 0.98 . We choose $\rho=0.95$ to take into account that the agents in our model are infinitely lived and that the intergenerational auto-regressive coefficient is lower. Solon (1992) estimates it to be around 0.4.

${ }^{16}$ The exact value of the variance is $\sigma_{\varepsilon}^{2}=.08125$. This is higher than the estimate of Storesletten et al. (2004) of about 0.02. We abstract from many important factors that are empirically relevant for the earnings distribution, e.g., human capital, life-cycle savings. Therefore, in order to generate the observed inequality, we need a higher variance of the earnings process.

${ }^{17}$ This corresponds to the difference between the one year mortgage and the one year Treasury Bill rate during the 1990s, Federal Reserve Economic Data.

${ }^{18}$ See Appendix B for data sources, definitions, and further details.

${ }^{19}$ This corresponds to the average of the value in the SCF and the SSBF.
} 
Table 2: Calibrated parameters

\begin{tabular}{lcc}
\hline Parameter & Symbol & Benchmark Value \\
\hline High entrepreneurial productivity & $\theta^{H}$ & 0.693 \\
Entrepreneurial productivity transition & $p^{H H}, p^{L L}$ & $0.878,0.988$ \\
Concavity of entrepreneurial technology & $\nu$ & 0.849 \\
Fraction with which agent can run & $\lambda$ & 0.943 \\
Discount factor & $\beta$ & 0.883 \\
Variance of transitory shock & $\sigma_{\chi}$ & 0.269 \\
\hline
\end{tabular}

\subsection{Baseline calibration results}

Table 3 has the values of the targets from the data and the actual results achieved in the baseline specification of the model. Overall, the model matches the targets very well.

Table 3: Baseline calibration targets

\begin{tabular}{lcc}
\hline Moment & Data & Model \\
\hline Fraction of Entrepreneurs (in \%) & 7.3 & 7.3 \\
Ratio of medians & 6.3 & 6.3 \\
Share of net worth of top 40\% & 94.0 & 96.6 \\
Capital-Output ratio & 3.1 & 3.1 \\
Exit Rate (in \%) & 15.0 & 15.5 \\
Bankruptcy Rate (in \%) & 0.164 & 0.164 \\
Median leverage (in \%) & 37.4 & 37.6 \\
\hline
\end{tabular}

The model captures several other features of the U.S. economy that were not explicitly targeted, in particular concerning entrepreneurship and credit. The marginal product of capital in the corporate sector $\left(r^{d}\right)$ is $3.8 \%$, which is close to the $4.0 \%$ reported by McGrattan \& Prescott (2001). Quadrini (2000) reports that about 35\%-40\% of total capital is invested in the entrepreneurial sector. In our baseline specification, this fraction is slightly higher, around $42.9 \%$.

The model captures two important features concerning the wealth distribution: entrepreneurs are several times richer than workers, and most of the wealth is held by the richest agents. The Gini coefficient for wealth is 0.88 , a bit higher than in the data where it is 0.8 .20 However, for the purpose of our policy experiments, it is important that the model replicates the middle and lower part of the wealth distribution, since the personal bankruptcy law mainly affects these

\footnotetext{
${ }^{20}$ If not otherwise stated, the empirical moments are from the SCF and described in detail in the data appendix.
} 
agents. In the model, the fraction of agents with zero wealth is $12.8 \%$, while it is $9.8 \%$ in the data. Moreover, entrepreneurs, in the model, hold $37.7 \%$ of the wealth, close to the $36.6 \%$ they hold in the data.

About $98.2 \%$ of the entrepreneurs in the model borrow, whereas in the data, $86.1 \%$ do so. In the model, $99.5 \%$ of borrowing is secured credit, whereas in the data, $92.7 \%$ is secured credit. ${ }^{21}$ The shocks hitting entrepreneurs must have a high variance in order to generate the defaults in the model. This implies a wide dispersion of income and large capital gains and losses. The median debt to income ratio in the model is 1.04 , while in the data, it is only 0.78 . The median income to net worth ratio in the data is 0.15 . The corresponding ratio in the model is 0.09 if capital gains are not counted as income and 0.35 if they are included.

\subsection{Investigating the model's mechanisms}

The behavior of the unconstrained agents. Figure 2 shows the decisions of unconstrained agents: $\sqrt{22}$ the top panel shows the demand for unsecured debt. ${ }^{23}$ The second panel shows the demand for secured debt. The third panel shows the corresponding price of unsecured credit. The bottom panel shows the resulting firm size.

In the model, otherwise identical agents choose different occupations, according to their wealth: poor agents become workers, as those in region (1) in Figure 2, while richer agents become entrepreneurs, regions (2)-(5) ${ }^{24}$ The main reason is that poor agents face worse credit conditions as they are more likely to default. This leads them to have small firms, so that they prefer to be workers.

Regions (2) to (4) are the key innovation of our paper. In region (2), entrepreneurs are poor and therefore have a strong incentive to default. Their default incentive is high because even in good states it is likely that they would benefit from filing for bankruptcy since all or most of their assets are below the exemption level. This high default incentive increases the cost of credit so much that they are effectively rationed out of the unsecured credit market. In models with only unsecured credit, this would imply that they can only self-finance, leading in turn to their firms' being too small, so that most of them would prefer to become workers.

Since we also allow for secured credit, this does not happen. Instead, they borrow secured,

\footnotetext{
${ }^{21}$ The share of secured credit in the model is so high because the cost difference between unsecured and secured credit is three percentage points. A smaller cost difference would lead to a higher fraction of unsecured credit because this would then become cheaper.

${ }^{22}$ These agents have high entrepreneurial productivity and low labor productivity.

${ }^{23}$ The discretization of the shock process leads to spikes in the policy functions. Since these spikes are not informative, we show smoothed policy functions in Figure 2. The unsmoothed policy functions can be found in the appendix.

${ }^{24}$ This is a standard result in the literature about occupational choice under credit market imperfections (e.g. Banerjee \& Newman, 1993).
} 


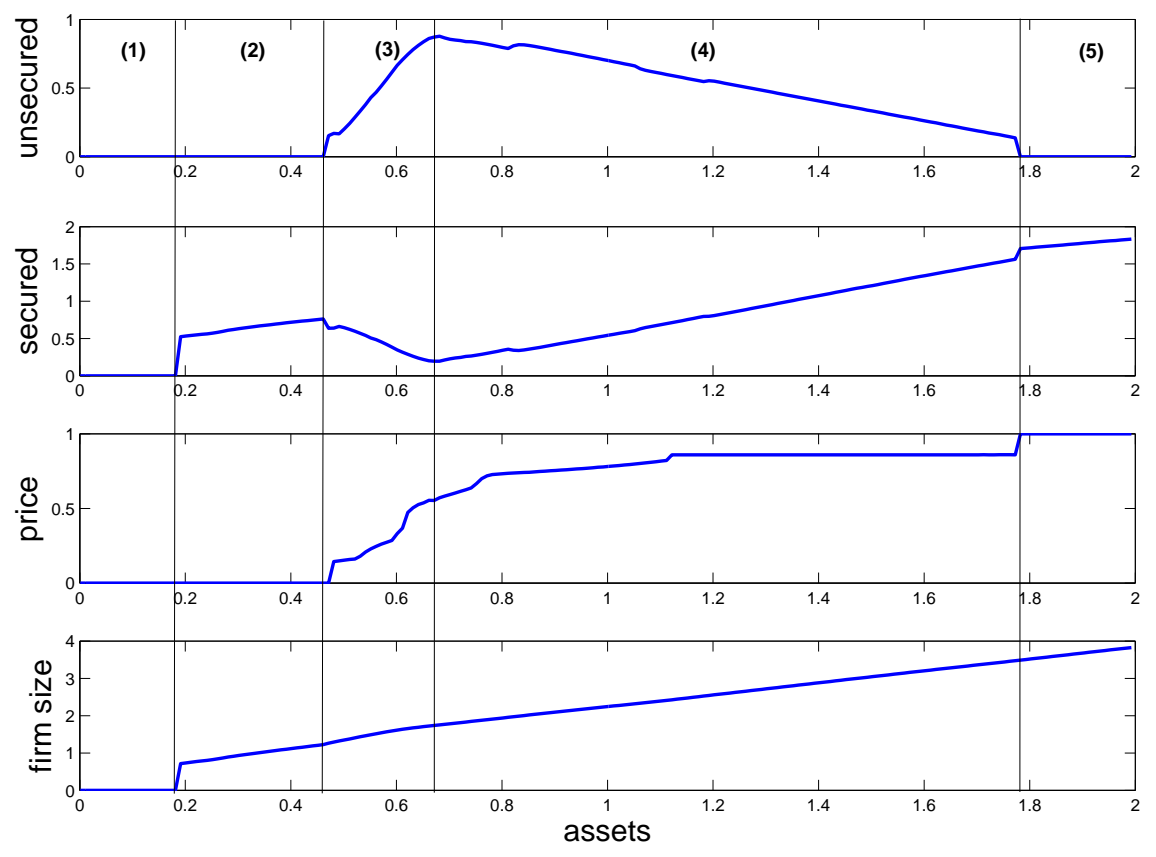

Figure 2: Decision of the unconstrained agent $\left(\theta=\theta^{H}, \varphi=\varphi_{1}\right)$

which leads to larger firms, which in turn makes entrepreneurship more attractive to them. Borrowing secured is not as good as borrowing unsecured, since secured credit does not provide any insurance. But it is better than not borrowing at all and only having a small firm. In region (2), secured borrowing allows agents to have bigger firms and therefore they choose to become entrepreneurs.

Entrepreneurs in region (3) are richer, and therefore have a lower default incentive. Thus, they can obtain some unsecured credit. They will default on this debt when they are hit by a sufficiently bad shock. In order to break even, the bank charges a higher interest rate and unsecured credit is more expensive. The interest rate depends negatively on the assets of the entrepreneur because in the event of a default, the bank will be able to seize the difference between the assets of the entrepreneur and the exemption level. The capital demand of these entrepreneurs is increasing because their cost of borrowing is declining, as can be seen in the third panel of Figure 2,

The richer are the agents in region (3), the more they borrow overall. But they also replace secured credit by unsecured credit even though the latter is more expensive. This is because unsecured credit provides them with valuable insurance against bad outcomes. Thus, the portfolio share of unsecured credit increases. Unsecured credit reaches its maximum at the 
border with region (4), where agents reverse this debt portfolio composition because default becomes ever more costly to them since they have to give up their wealth above the exemption level in the case of a default. The share of unsecured credit declines continuously within region (4). The very rich entrepreneurs in region (5) will never find it profitable to default. Their wealth is so high that defaulting is too costly for them. Therefore they borrow only secured, since it is cheaper than unsecured.

The role of bankruptcy. Bankruptcy affects the problem of the unconstrained agents, because it changes credit conditions and the amount of insurance available. We examine these effects with the following experiment: we compare the behavior of the unconstrained agents in two different situations, the baseline calibration and one in which exemption is zero so bankruptcy is so costly that nobody defaults. Figure 3 shows the policy functions in these situations.
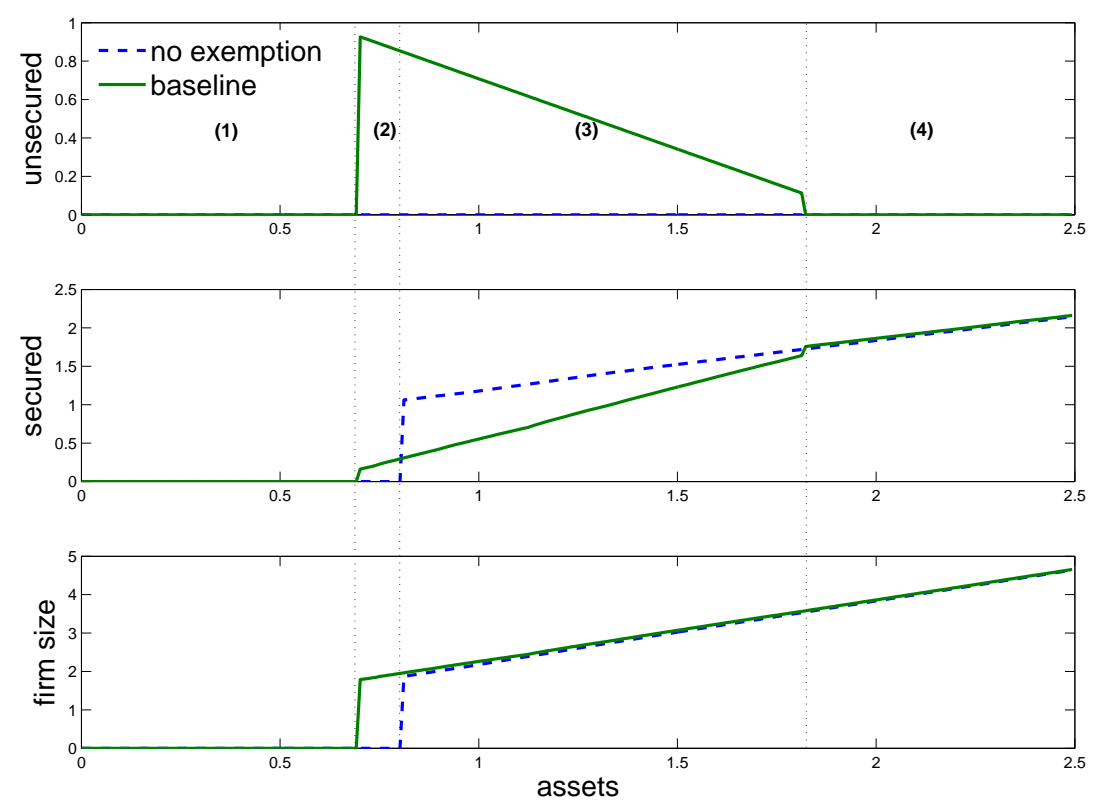

Figure 3: Effects of bankruptcy $\left(S=U N, \theta=\theta^{H}, \varphi=\varphi_{2}\right)$

The effects of bankruptcy depend on the wealth of the agent. First, the default behavior of rich agents, as in region (4) of Figure 3 , is not affected. They are entrepreneurs and they repay their debt even in the bad states. As explained above, even if bankruptcy is available, it is too costly for them.

Second, a more generous bankruptcy affects the behavior of the less rich agents, region (3). 
They are entrepreneurs in both situations. But when bankruptcy is not too costly, they replace part of their secured borrowing by unsecured borrowing. If they are hit by a bad shock, they default, and can keep assets up to the exemption level. This partial wealth insurance can enable them to remain entrepreneurs in the next period. Even though they are excluded from the unsecured credit market now, they might have sufficient wealth left to enter entrepreneurship. This is the fresh start effect of Chapter 7 , and is explored further in the following sections.

Third, the occupational choice of even less rich agents, region (2), is also affected. When bankruptcy is too costly, they are not insured against bad outcomes. Therefore they do not want to borrow, even though they could borrow at the rate for secured credit. They become workers instead. When bankruptcy is feasible, they are insured against bad outcomes and they borrow, even though they have to pay a high interest rate. This increases the rewards of entrepreneurship enough to change their occupational choice.

Fourth, the occupational choice of the very poor agents, region (1) is not affected: they are workers in both situations.

In this particular experiment, extremely expensive bankruptcy reduces entrepreneurship and firm size: the intensive and the extensive margins are negative. The negative effect of lowering the amount of insurance available dominates the positive effect of better credit conditions. 25

\subsection{The policy experiment}

Our main policy experiment is to analyze the effects of changing the exemption level on the steady state equilibrium of the model. The aggregate effects of changing the exemption level are shown in Figure 4. In addition, Table 4 shows the results for five values of the exemption level.

Welfare. Welfare is measured as the change in consumption equivalent ${ }^{26}$ and is shown in the top left panel. The solid line in the top left panel of Figure 4 shows the steady-state comparison. The current exemption level in the U.S. is too low. Increasing the exemption increases welfare as the insurance effect dominates the effects of the worsening credit market condition. More agents become entrepreneurs (middle left panel) and welfare increases. However, increasing the exemption level beyond $X=7.1$ reduces welfare. The welfare gains from increasing the exemption level to the optimal are substantial: about $1.2 \%$ of annual consumption.

In order to investigate how far these welfare changes depend on general equilibrium effects or

\footnotetext{
${ }^{25}$ However the general equilibrium effects depends also on the distribution and can not be derived from this graph.

${ }^{26}$ This means, for example, that reducing the exemption level to zero lowers welfare as much as a decrease in annual consumption of $0.15 \%$.
} 

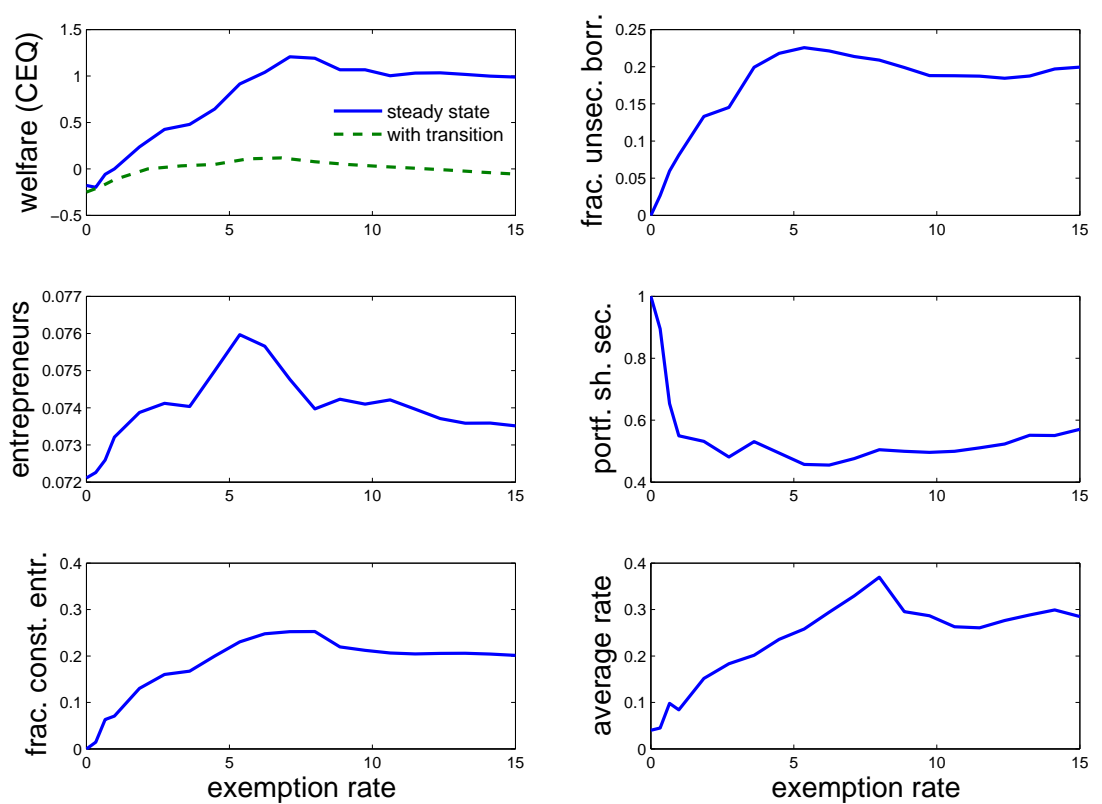

Figure 4: Changes in the exemption levels

the absence of transitional dynamics, we investigate two further scenarios. First, we repeated the same policy experiment without imposing capital market clearing, therefore leaving the marginal product of capital constant. Welfare is almost identical to the steady state scenario and is not shown in the graph. Second, following Domeij \& Heathcote (2004), we computed welfare taking into account the transition phase from the old to the new steady state. This changes the size of the welfare effects significantly, as shown by the broken line in the top left panel of Figure 4. The welfare gain falls significantly to $0.12 \%$ of annual consumption. However, and most importantly, the optimal exemption level is hardly affected. It falls only to $X=6.8$.

Welfare increases for the rich, measured as the top quartile of the wealth distribution, and the poor, measured as the bottom quartile, as can be seen in the last two rows of Table 4 . The bulk of the welfare gains accrue to the rich because at higher exemption levels, richer agents will use the default option to partially insure their wealth.

However, the fact that the poor do not lose from a higher exemption level is in contrast to the literature, for example Akyol \& Athreya (2011). Typically, a more generous exemption level leads to credit rationing of poor agents. However, if secured credit is available, they are not rationed out of all borrowing, only out of the unsecured credit market. Losing access to all credit imposes a first order welfare loss, losing only the insurance value of the default option but still obtaining (secured) credit is only a second order welfare loss. Further evidence for the 
importance of secured credit will be discussed in Section 4.5 .

Entrepreneurship and the credit market. Increasing the exemption level to the optimal level increases the fraction of entrepreneurs by 0.31 percentage points. Thus, there is a positive extensive margin, as can be seen in the middle left panel of Figure 4. There is a related important effect of Chapter 7 bankruptcy: the fresh start effect: by allowing defaulters to keep more of their wealth, Chapter 7 makes it easier for agents to remain in entrepreneurship in the following periods. The quantitative importance of this effect is shown in the bottom left panel of Figure 4. The fraction of entrepreneurs who have defaulted in the past increases from zero to more than $20 \%$ of all entrepreneurs.

This evidence is further corroborated by the top right panel of Figure 4, which shows that the fraction of entrepreneurs who borrow unsecured first increases and then levels off. This implies that an increasing fraction of entrepreneurs gain the benefit of partial wealth insurance. The middle right panel shows that out of those entrepreneurs who borrow unsecured, the debt portfolio share is relatively constant, at about one half. As the exemption level is increased, more entrepreneurs borrow unsecured at a constant fraction. If they default, they can keep more of their assets. Therefore, an increasing fraction of failed entrepreneurs who have defaulted can remain entrepreneurs.

However, as can be seen by comparing the top left and the middle left panels of Figure 4, the entrepreneurship rate peaks earlier than welfare. This implies that also the intensive margin is important in explaining the welfare results. Indeed, the sixth row of Table 4 shows that the fraction of capital employed in the entrepreneurial sector peaks at the optimal exemption level.

The default rate, third row of Table 4, is hump-shaped in the exemption level, as is the mean interest rate, bottom left panel of Figure 4. The exit rate, however, is U-shaped, fourth row of Table 4. The reason for the declining part is the fresh start effect. Agents who have defaulted keep enough assets to remain entrepreneurs despite being excluded from the unsecured credit market. The increasing part at very high exemption levels is due to the fact that now more entrepreneurs are excluded from the unsecured credit market since their default incentive is too high. This is consistent with the decline in the default rate in columns six and seven of the third row in Table 4. If those entrepreneurs who are excluded from the unsecured credit market are hit by a bad shock, their wealth is not insured. Thus, they have insufficient wealth in the next period to remain entrepreneurs, and therefore they exit. 
Table 4: Effects of changes in the exemption level

\begin{tabular}{lccccc}
\hline $\mathbf{X} / \mathbf{W}$ & $\mathbf{0}$ & $\mathbf{0 . 9 8}$ & $\mathbf{4 . 4 8 5}$ & $\mathbf{7 . 1 1}$ & $\mathbf{1 0 . 6 1 9}$ \\
\hline Exit rate & 16.05 & 15.49 & 15.23 & 14.39 & 15.5 \\
Fraction of entrepreneurs & 7.211 & 7.321 & 7.499 & 7.476 & 7.421 \\
Default rate & 0 & 0.164 & 0.472 & 0.564 & 0.456 \\
Capital-output ratio & 3.09 & 3.09 & 3.08 & 3.083 & 3.08 \\
Ratio of medians & 6.5 & 6.3 & 6.2 & 7.1 & 7.9 \\
Share of capital in entr. sector & 42.82 & 42.86 & 43.21 & 43.51 & 43.49 \\
Min. wealth for entr: $\varphi=\varphi_{1}$ & 0.2312 & 0.1912 & 0.2112 & 0.2212 & 0.2312 \\
Min. wealth for entr: $\varphi=\varphi_{3}$ & 1.733 & 1.713 & 1.572 & 1.662 & 1.673 \\
Welfare poor & -0.32 & 0 & 0.23 & 0.46 & 0.18 \\
Welfare rich & -0.010 & 0 & 0.932 & 2.46 & 2.42 \\
\hline
\end{tabular}
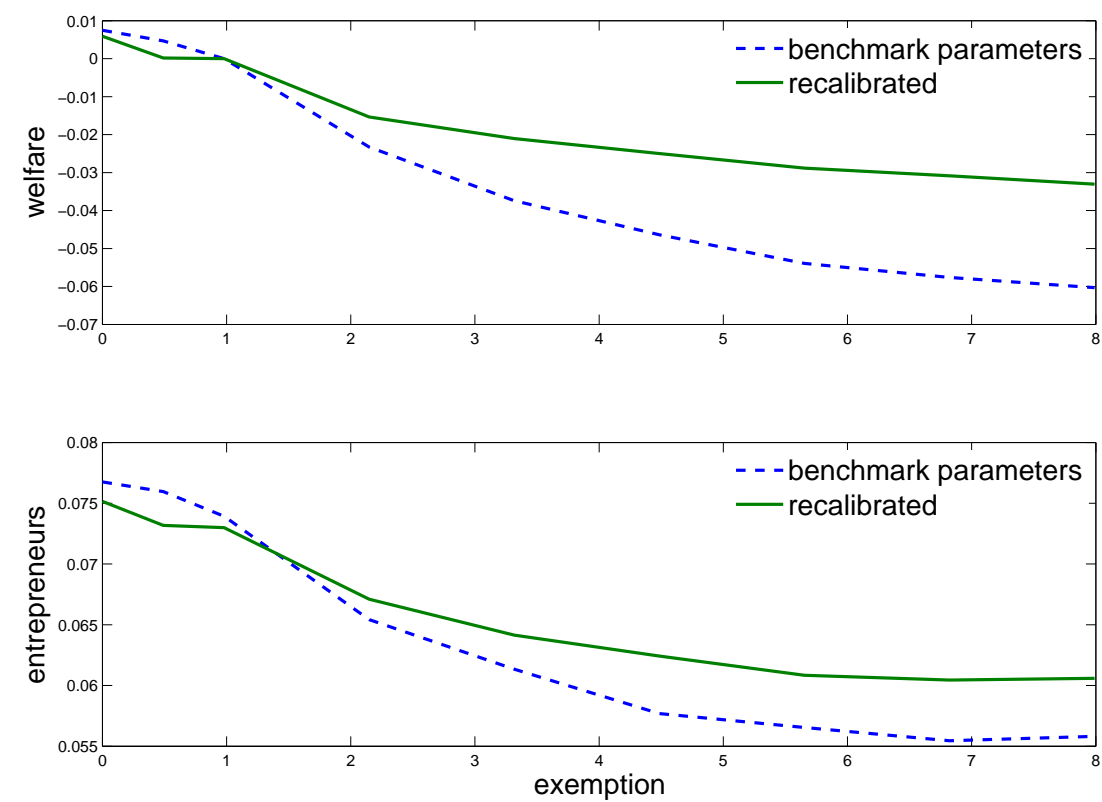

Figure 5: Welfare effects of changes in $X$ if only secured credit is available 


\subsection{The role of secured credit}

Almost all papers in the bankruptcy literature allow only unsecured borrowing ${ }^{27}$ Notable exceptions are Athreya (2006), Pavan (2008), and Hintermaier \& Koeniger (2011) in the consumption literature. However, not only is secured credit empirically relevant, but also, as we show in this section, it is crucial for the results. To show this, we set up a model identical to the one discussed so far except that there is no secured credit available, neither for the borrowing constrained nor for the unconstrained entrepreneur. This implies that the former cannot borrow at all and must finance their projects with their own wealth. We will recalibrate the model and then conduct the same policy experiment as before. The results in Figure 5 (solid lines) are striking. The optimal bankruptcy law now would be to set the exemption level to zero. This would increase welfare and lead to a higher number of entrepreneurs.28

Table 5: Calibration: Unsecured credit only

\begin{tabular}{lccc}
\hline Moment & Target & Unsec credit only & Sec and Unsec \\
\hline Entrepreneurs (in \%) & 7.30 & 7.30 & 7.65 \\
Defaulters (in \%) & 2.25 & 2.25 & 2.75 \\
\hline
\end{tabular}

Table 5 shows what happens if we take the parameters calibrated for the model without secured borrowing and use them in a model which allows secured borrowing. Since the financial market is now relatively more complete, we see that there are more entrepreneurs and more defaults. The reason for these aggregate results can be seen in Figure 6, which, shows the policy functions in both situations. The solid line corresponds to the situation when only unsecured credit is available. Therefore, the secured borrowing is zero in the bottom panel. The broken line, which is computed for the same parameters, corresponds to the situation when both unsecured and secured credit are available. The unconstrained agents in region (1) are workers, whether or not secured credit is available. Similarly, in region (3), they are entrepreneurs. However, agents in region (2) do not obtain sufficient unsecured credit because their default incentive is too high. If secured credit is not available, these agents become workers. However, if secured credit is available, these agents can borrow secured and become entrepreneurs.

Figure 7 shows the effects of increasing the exemption level to $X=2.15$ in both cases. Without secured credit, the increase in the exemption level worsens the credit conditions for

\footnotetext{
${ }^{27}$ See for example Akyol \& Athreya (2011), Meh \& Terajima (2008), Athreya (2002), Livshits et al. (2007), Chatterjee et al. (2007), Athreya \& Simpson (2006), Li \& Sarte (2006), Mateos-Planas \& Seccia (2006).

${ }^{28}$ This result is not driven by the recalibration. The broken line in Figure 5 shows the results of the same policy experiment in the model without secured credit using the benchmark parameters from Table 2. Again, it would be optimal to set the exemption level to zero.
} 

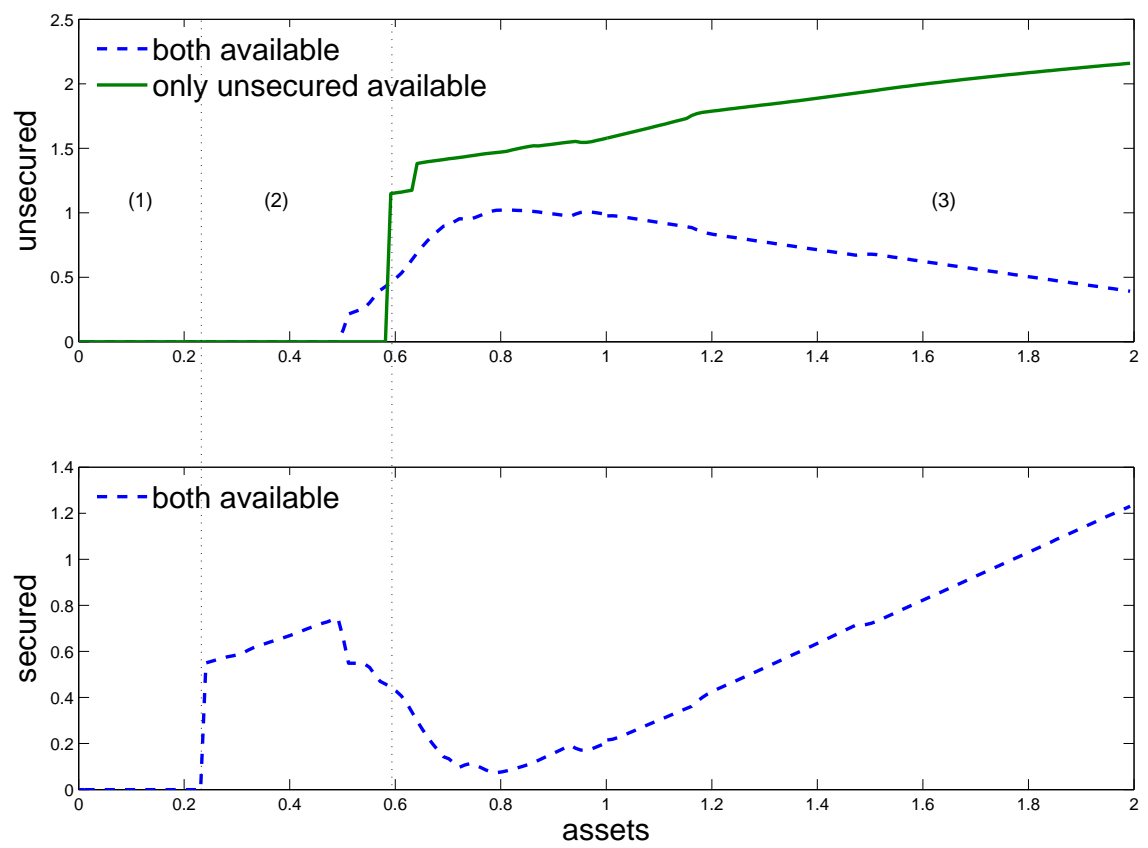

Figure 6: Policy functions for baseline exemption level

many more agents, region (3a) in Figure 7. Thus, agents in this region obtain only a small amount of credit. This leads to a significant decline in firm size, a negative intensive margin. The effects of an increase in the exemption level differ markedly when secured credit is available, the broken lines in Figure 7. While unsecured credit behaves similarly, agents now borrow a lot more secured, so that the negative intensive margin is significantly smaller. Thus, the availability of secured credit dampens the negative extensive and intensive margin substantially.

The absence of a negative extensive margin when secured credit is available can also be seen in the third and fourth to last rows in Table 4. These show the critical level of wealth at which agents enter into entrepreneurship. This threshold is increasing in labor productivity because the agents' outside option is increasing in their wage income. However, conditional on labor productivity, this critical threshold does not change much even for large changes in the exemption level.

The two other quantitative general equilibrium models in the entrepreneurial bankruptcy literature (Akyol \& Athreya, 2011; Meh \& Terajima, 2008) find significant welfare gains from making the bankruptcy law harsher. But none of them includes secured credit. Our results imply that their results might not be robust to including secured borrowing, as ignoring secured credit overstates the negative effects of high exemption levels. 

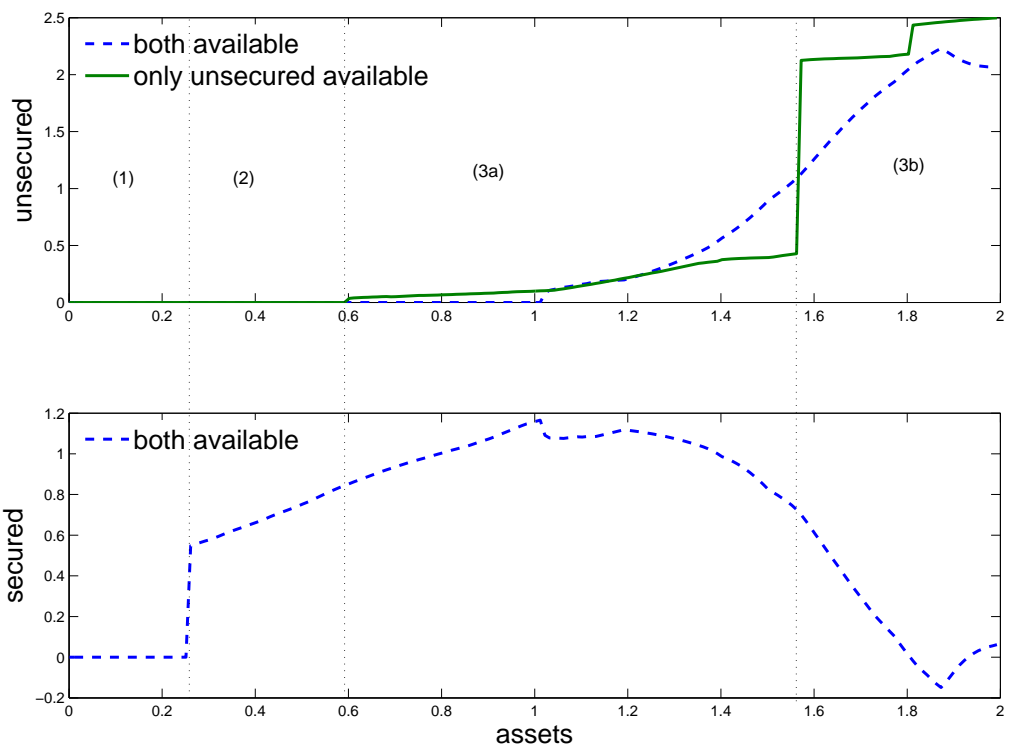

Figure 7: Policy functions for a high exemption level

\subsection{The role of preferences}

In this section, we show the effects of changing the agents' preferences on our main results. We separate the elasticity of intertemporal substitution from the coefficient of relative risk aversion. With a utility function of the CRRA class, one is the inverse of the other. In this case, an increase in risk aversion, as, for example, examined in Athreya (2006), conflates two effects. On the one hand, since agents are more risk averse, they value insurance more, so the optimal exemption level is likely to be higher. On the other hand, with CRRA preferences, an increase in risk aversion simultaneously lowers the elasticity of intertemporal substitution. Thus, agents are less willing to transfer consumption across time. But a higher exemption level will increase the interest rate agents face because banks have to charge higher interest rates in order to break even. Thus, a decrease in the elasticity of intertemporal substitution is likely to lead to a lower optimal exemption level. By not separating the two, one examines only their net effect. It is possible that each of these two effects is big but that they cancel each other so that the net effect is small.

We recalibrate the steady state of the model for different values of both parameters and for each case we solve for the optimal exemption level. The results when we vary the coefficient of relative risk aversion while keeping the elasticity of intertemporal substitution constant at its benchmark value are in Panel (A) of Table 6. The results when we vary the elasticity of 
intertemporal substitution but keep risk aversion constant are in Panel (B). The first result is that our benchmark result that the optimal exemption level is significantly higher than the current level is robust. The optimal exemption level never drops below 7.0. The second result is that, as shown in panel (A) of Table 6, the more risk averse are the agents, the more they value the insurance coming from a higher exemption level. The third result, shown in Panel (B) of Table 6, is that the optimal exemption level is also increasing in the elasticity of intertemporal substitution. The more willing are the agents to substitute consumption over time, the less costly are the higher interest rates coming from a higher exemption level.

Table 6: Optimal exemption levels for different values of CRRA and EIS

\begin{tabular}{|c|c|c|c|}
\hline \multicolumn{2}{|c|}{ Panel A: CRRA } & \multicolumn{2}{|c|}{ Panel B:EIS } \\
\hline CRRA & Optimal $X$ & EIS & Optimal $X$ \\
\hline 2 & 7.1 & 0.6 & 7.0 \\
\hline 3 & 7.75 & 0.9 & 7.1 \\
\hline 4 & 9.0 & 1.1 & 8.6 \\
\hline
\end{tabular}

\section{Conclusion}

In this paper, we quantitatively explored the effects of the personal bankruptcy law on entrepreneurship in a model which includes secured credit in addition to unsecured credit. We developed a dynamic general equilibrium model with heterogeneous agents and occupational choice which explicitly incorporates the U.S. bankruptcy law. The model endogenously generates interest rates that reflect the different default probabilities of the agents. Our model accounts for the main facts about entrepreneurial bankruptcy, entrepreneurship, wealth distribution, and macroeconomic aggregates in the U.S.

We used the model to quantitatively evaluate the effects of changing Chapter 7 exemption levels. The simulation results show that the current exemption level is too low. Increasing the exemption level to the optimal one has positive welfare effects on the order of $1.2 \%$ of average consumption if steady-states are compared. These gains fall to $0.12 \%$ if transitional dynamics are taken into account, but the optimal exemption level is only slightly lower. While most gains accrue to rich households, the poor would also be better off.

The most important contribution of our paper is to show that secured credit changes the trade-off between insurance and credit conditions significantly. We showed that analyzing exemption levels in models without secured credit yields misleading results because it overstates 
the worsening of credit market conditions. In fact, in these models the optimal exemption level is low. Instead, once we allow for secured credit, the optimal exemption level is high.

It is worth noting that we abstracted from several interesting aspects. First, the characteristics of the entrepreneurial projects are exogenous. It would be interesting to see whether a high exemption level would still be optimal if entrepreneurs could choose the riskiness of their projects. Secondly, and related to the first aspect, we abstracted from leisure for workers and entrepreneurs. A generous bankruptcy law might lead entrepreneurs to under-provide effort. Last, we had only a one-good model. Therefore, we modeled secured credit as pledgeable income and assets. It would be interesting to incorporate durable goods in the form of housing, and then model secured credit as a mortgage on the house. We leave these issues for future research. 


\section{Appendix}

\subsection{Computational strategy}

The state vector for an individual is given by $\eta=(a, \theta, \varphi, S)$. The aggregate state is a density $\mu(a, \theta, \varphi, S)$ over the individual state variables. Individual asset holdings are discretized with a grid $G_{a}$ of dimension $n_{a}$. Therefore, the dimension of the individual state space is $n=n_{a} \times n_{\theta} \times n_{\varphi} \times 2$, where $n_{\theta}=2$ is the number of states for the entrepreneurial productivity and $n_{\varphi}=4$ is the number of states for the working productivity.

In order to solve the model we use the following:

\section{Algorithm 1}

1. Assign values to all parameters.

2. Guess a value for the marginal product of labor. This is also the rate of return on deposits $r^{d}$.

3. Given $r$, the FOC of the corporate sector uniquely pins down the wage rate $w$. The representative competitive firm in the corporate sector chooses $K_{c}$ and $L_{c}$ such that

$$
\begin{gathered}
r^{d}=\xi A\left(\frac{K_{c}^{d}}{L_{c}^{d}}\right)^{\xi-1} \\
w=(1-\xi) A\left(\frac{K_{c}^{d}}{L_{c}^{d}}\right)^{\xi} .
\end{gathered}
$$

Therefore $r^{d}$ uniquely determines the capital-labor ratio in the corporate sector, which, in turn, pins down $w$.

4. Given the price vector $\left(r^{d}, w\right)$, solve for the optimal value functions and corresponding policy functions by value function iteration. Within the period, solve backwards in time.

(a) Guess value functions for the agents.

(b) Solve the consumption-savings problem of the constrained and unconstrained agents for a grid of cash on hand.

(c) Approximate the resulting continuation value functions.

(d) Since the worker faces no uncertainty within the period, these value functions yield the values for the workers.

(e) Given the continuation value, solve the problem of the unconstrained entrepreneur:

- Set up a grid for secured credit; 
- For each value of secured credit, set up a grid for unsecured credit;

- For each value of unsecured credit, price the credit according to the zero profit condition. Start by offering it at the risk free rate. If the entrepreneur would default, increase the interest rate until an interest rate at which the bank expects to break even is found.29

- Identify the optimal grid point and then search around that for first- and secondbest points, in order to get a more robust choice of unsecured credit.

(f) The problem of the constrained entrepreneur is solved similarly.

(g) Occupational choice yields the updated value functions.

(h) Iterate until convergence.

(i) In this process, also the policy functions are obtained.

5. The policy functions, the exogenous transition matrix for the shocks (both for $\theta$ and for $\varphi)$, the iid investment shock $\chi$, and the credit status shock $\varrho$, induce a transition matrix $P_{\eta}$ over the states $\eta$.

6. The transition matrix $P_{\eta}$ maps the current density $\mu_{\eta}$ into a density for the next period $\mu_{\eta}^{\prime}:$

$$
\mu_{\eta}^{\prime}=P_{\eta}^{\prime} \times \mu_{\eta}
$$

Calculate the steady state density over the state space $\mu_{\eta}^{*}$ by solving for

$$
\mu_{\eta}^{*}=P_{\eta}^{\prime} \times \mu_{\eta}^{*}
$$

7. From the policy functions and the steady state distribution, check the market clearing conditions.

8. If there is no equilibrium, adjust the interest rate and go back to point 3. Repeat this until the capital market clears ${ }^{30}$

\subsection{Policy functions and numerical robustness}

In this section we consider the non-smoothed policy function and the robustness of our results with respect to changes in the numerical procedures and parameters. Figure 8 is the analogue of Figure 2 in Section 4 of body of the paper, without smoothing out the spikes. The spikes are present because we discretized the shock process with five nodes. An entrepreneur in

\footnotetext{
${ }^{29}$ Credits that would lead to a default probability of 1 are not allowed.

${ }^{30}$ In the implementation, the hunt algorithm is used to find the interest rate that clears the capital market.
} 
region (5) will never default. Agents with wealth between 1.15 and 1.78 will default only when the worst shock realization occurs. Agents with wealth between 0.77 and 1.15 will default only when the worst or the second worst shock realization occurs. The kink in the policy functions at 1.15 reflects this switch in default behavior. Something similar happens at wealth levels 0.77 and 0.6. Increasing the number of nodes in the shock process is computationally very costly without affecting the results a lot, as can be seen in column 8 of Table 7 .

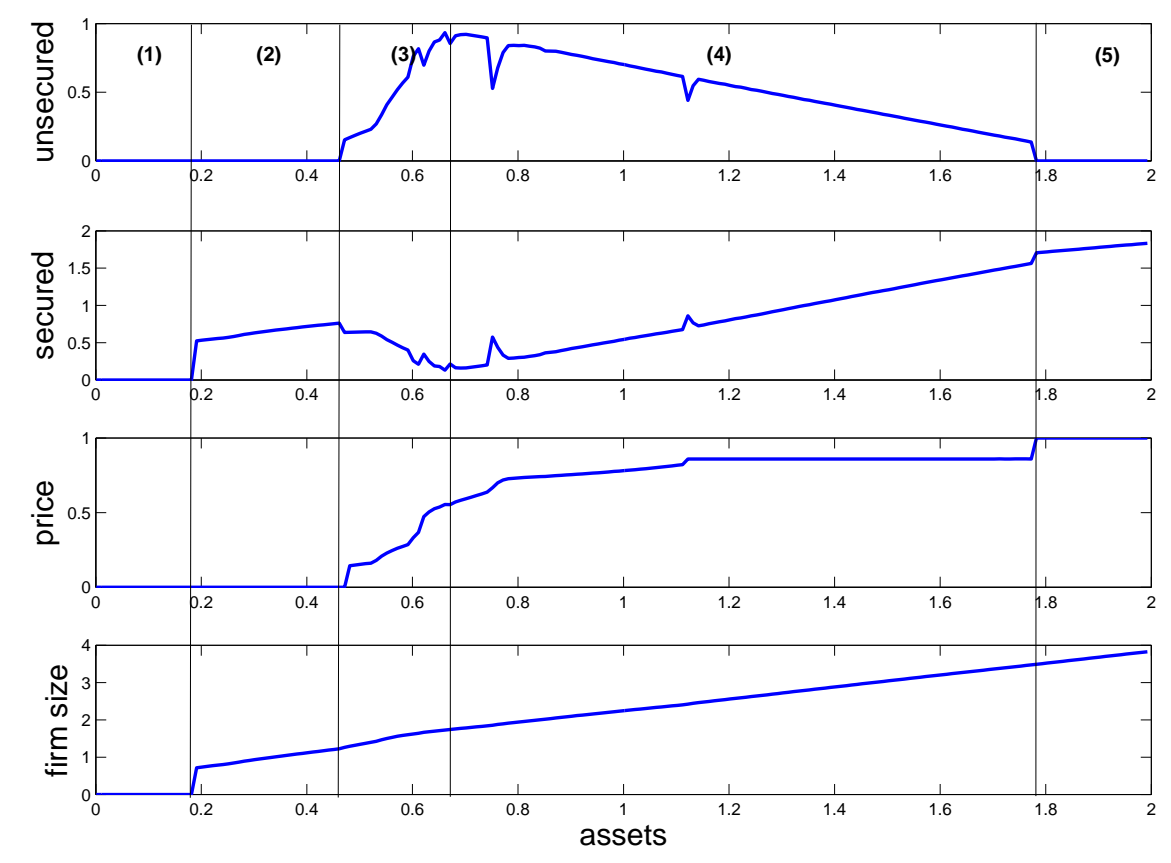

Figure 8: Decision of the unconstrained agent $\left(\theta=\theta^{H}, \varphi=\varphi_{1}\right)$, non smoothed

Table 7 shows the results of some numerical robustness checks, one for each column. The table shows the values of the parameters, with the changed one highlighted, as well as the percentage change with respect to the baseline calibration of some of the main results of the model (e.g., welfare, fraction of entrepreneurs, fraction of defaulters). In columns 1-2 we change the tolerance level of some of the iterative procedures in the solution algorithm: the condition for equilibrium in the asset market: excess demand (column 1) and the convergence criterion for the value function iteration (column 2). The bottom panel of Table 7 shows that none of the results is significantly affected. The most affected is the fraction of defaulters, which changes by $0.004 \%$ in the worst case (column 1). In columns 3 to 5 we show the effects of changing the size of the main grids used to discretize the continuous choice variables (secured and unsecured credit, column 3) and the continuous state variable (assets) in the final phase (column 4) and 
in an intermediate phase (column 5). The bottom panel shows that the grids for assets hardly affects any of the results: doubling the size of the grid or eliminating the intermediate phase altogether changes the fraction of defaulters by $0.15 \%$ and the interest rate by $0.29 \%$. Reducing the grid for choice variables affects the fraction of defaulters by about $0.4 \%$. Columns 6 and 7 show the effects of changing the interpolation methods in different phases of the solution algorithm (from linear interpolation to splines), but they hardly have any effect. Column 8 shows the effect of having a finer grid to discretize the transitory shock to entrepreneurial production. In this case, the changes are more significant, as expected, given that this is a major change in the numerical solution. But even in this case, none of the changes exceed $1 \%$. It should be noticed that the order of magnitude of the changes in the model outcomes due to all these robustness checks is significantly smaller than the changes due to our policy experiment. For example, the corresponding fraction of entrepreneurs in column 8 is 0.07323 versus a baseline of 0.07321 , while the change due to the policy experiment was significantly larger: entrepreneurship increased up to 0.076 .

Table 7: Numerical robustness checks

\begin{tabular}{|c|c|c|c|c|c|c|c|c|c|}
\hline Parameters & baseline & 1 & 2 & 3 & 4 & 5 & 6 & 7 & 8 \\
\hline Size asset grid final (lower part) & 1000 & 1000 & 1000 & 1000 & 2000 & 1000 & 1000 & 1000 & 1000 \\
\hline Size asset grid final (upper part) & 1000 & 1000 & 1000 & 1000 & 2000 & 1000 & 1000 & 1000 & 1000 \\
\hline Size assets grid preliminary (lower part) & 300 & 300 & 300 & 300 & 300 & 1000 & 300 & 300 & 300 \\
\hline Size assets grid preliminary (upper part) & 200 & 200 & 200 & 200 & 200 & 1000 & 200 & 200 & 200 \\
\hline Size capital and credit grids & 200 & 200 & 200 & 150 & 200 & 200 & 200 & 200 & 200 \\
\hline Number of transitory shocks states & 5 & 5 & 5 & 5 & 5 & 5 & 5 & 5 & 7 \\
\hline Interp. method for intermediate value func. & 1 & 1 & 1 & 1 & 1 & 1 & 1 & 3 & 1 \\
\hline Interp. method for final value func. & 0 & 0 & 0 & 0 & 0 & 0 & 1 & 0 & 0 \\
\hline Tolerance value function iteration & $1 \mathrm{E}-09$ & $1 \mathrm{E}-09$ & 1E-0 7 & $1 \mathrm{E}-09$ & $1 \mathrm{E}-09$ & $1 \mathrm{E}-09$ & $1 \mathrm{E}-09$ & $1 \mathrm{E}-09$ & $1 \mathrm{E}-09$ \\
\hline Tolerance excess demand for equilibrium & $1 \mathrm{E}-05$ & 1E-03 & $1 \mathrm{E}-05$ & $1 \mathrm{E}-05$ & $1 \mathrm{E}-05$ & $1 \mathrm{E}-05$ & $1 \mathrm{E}-05$ & $1 \mathrm{E}-05$ & $1 \mathrm{E}-05$ \\
\hline \multicolumn{10}{|l|}{ \% change of results } \\
\hline Fraction of defaulters & 0 & 0.004 & 0.004 & 0.426 & 0.155 & 0.141 & 0.026 & 0.034 & 0.614 \\
\hline Fraction of entrepreneurs & 0 & 0.001 & 0.000 & 0.007 & 0.000 & 0.026 & 0.035 & 0.002 & 0.210 \\
\hline Interest rates & 0 & 0.002 & 0.000 & 0.009 & 0.293 & 0.004 & 0.225 & 0.005 & 0.867 \\
\hline Wage rate & 0 & 0.002 & 0.001 & 0.000 & 0.052 & 0.000 & 0.040 & 0.002 & 0.156 \\
\hline Welfare & 0 & -0.001 & 0.000 & -0.001 & -0.004 & -0.001 & -0.002 & 0.000 & -0.017 \\
\hline Welfare of the poor & 0 & 0.000 & 0.000 & -0.001 & -0.007 & -0.006 & -0.003 & 0.000 & -0.001 \\
\hline Welfare of the rich & 0 & 0.000 & 0.000 & -0.001 & -0.006 & -0.008 & -0.005 & 0.000 & -0.044 \\
\hline
\end{tabular}

\subsection{Data}

Our definition of entrepreneur is someone who owns a business and whose main occupation is to run this business. We use three data sources: The Small Business Economy (2006) by the U.S. Small Business Administration, Office of Advocacy ${ }^{31}$, the Survey of Consumer Finances (SCF) over the period 1992-2004, and Panel Study on Income Dynamics (PSID) for the period 1980-1997.

\footnotetext{
${ }^{31}$ The original sources of the data are: the Bureau of Census and U.S. Department of Commerce for data on employers, and the Administrative Office of the U.S. Courts for business bankruptcy filings.
} 
From the SCF we get the fraction of entrepreneurs in the population, the ratio of the median net worth of entrepreneurial households to the median net worth and the statistics of the wealth distribution. In the SCF, we classify an household as an entrepreneur if the head owns and runs a business and has at least one employee. The average fraction of the population engaged in entrepreneurial activity is $7.29 \% .32$ We also find that on average for the period 1992-2004 the ratio of the median net worth of entrepreneurial households to the median net worth for the total population is equal to $6.29 .^{33}$ To be sure that our model captures the most relevant features of the wealth distribution, we target the share of net worth held by the top $40 \%$, which in the SCF is on average for our sample period equal to $94 \%$. From the SCF, we also get a measure of the leverage of entrepreneurs. The median leverage for entrepreneurs with some debt in the sample is equal to $14 \%$. However, Heaton \& Lucas (2002) find, for the same statistic, a value of $61 \%$ from the Survey of Small Business Finances. We set the calibration target to the average of the two, i.e., $37.5 \%$.

Since the SCF does not have a longitudinal dimension, it does not allow of calibrating the exit rate. Therefore, we use the PSID, which has already been used in the literature as a source of data on entrepreneurship Quadrini, 2000). However, the PSID does not report the number of employees per firm. The closest we can get to our definition is to assume that an entrepreneur is an agent who owns a business and declares being self employed. According to this definition we get, for the period 1980-1997, a fraction of entrepreneurs equal to 8\%, which is close to our corresponding measure in the SCF. Given this definition, we get an exit rate equal to 0.1534.

The bankruptcy target is taken from the U.S. Small Business Administration, Office of Advocacy, and adjusted by the findings of Lawless \& Warren (2005) as explained in detail in Section 2 ,

\section{References}

J. Adda \& R. Cooper (2003). Dynamic Economics. MIT Press, Cambridge, MA.

\footnotetext{
${ }^{32}$ This number is similar to the numbers obtained by using other definitions of entrepreneurship used in the literature. Cagetti \& De Nardi (2006) define as entrepreneurial a household whose head owns and runs a business and is self-declared as self employed. Gentry \& Hubbard (2004) define as entrepreneurial a household who owns and runs a business with a total market value of at least 5000\$. Using these definitions we get on average for the same period a fraction of entrepreneurs of $7.5 \%$ and $9.4 \%$, respectively.

${ }^{33}$ Using other definitions of entrepreneurship, the ratio of the median wealth of entrepreneurs is lower: 4.7 and 4.8 when using the definitions of Cagetti \& De Nardi (2006) and Gentry \& Hubbard (2004), respectively.

${ }^{34}$ Quadrini (2000) who also uses PSID adopts two definitions of entrepreneur: someone who is self-declared as self employed and someone who owns a business. These definitions yield a fraction of entrepreneurs for the same period of 0.12 and 0.14 , respectively. The exit rates are equal to 0.21 for the business owners, 0.12 for the self employed
} 
A. Akyol \& K. Athreya (2011). 'Credit and Self-Employment'. Journal of Economic Dynamics and Control 35(3):363-385.

K. Athreya (2006). 'Fresh Start or Head Start? Uniform Bankruptcy Exemptions and Welfare'. Journal of Economic Dynamics and Control 30(11):2051-2079.

K. B. Athreya (2002). 'Welfare Implications of the Bankruptcy Reform Act of 1999'. Journal of Monetary Economics 49(8):1567-1595.

K. B. Athreya \& N. B. Simpson (2006). 'Unsecured Debt with Public Insurance: From Bad to Worse'. Journal of Monetary Economics 53(4):797-825.

A. Banerjee \& A. Newman (1993). 'Occupational Choice and the Process of Development'. Journal of Political Economy 101(2):274-298.

J. Berkowitz \& M. J. White (2004). 'Bankruptcy and Small Firms' Access to Credit'. RAND Journal of Economics 35(1):69-84.

M. Cagetti \& M. De Nardi (2006). 'Entrepreneurship, Frictions, and Wealth'. Journal of Political Economy 114(5):835-870.

S. Chatterjee, et al. (2007). 'A Quantitative Theory of Unsecured Consumer Credit with Risk of Default.'. Econometrica 75(6):1525-1589.

D. Domeij \& J. Heathcote (2004). 'On The Distributional Effects Of Reducing Capital Taxes'. International Economic Review 45(2):523-554.

D. Evans \& R. Schmalensee (1999). Paying with plastic: The digital revolution in buying and borrowing. MIT Press, Cambridge, MA.

W. Fan \& M. J. White (2003). 'Personal Bankruptcy and the Level of Entrepreneurial Activity'. The Journal of Law \& Economics 46:543-567.

W. M. Gentry \& G. R. Hubbard (2004). 'Entrepreneurship and Household Saving'. Advances in Economic Analysis \& Policy 4(1):1035-1053.

A. Glover \& J. Short (2011). 'Bankruptcy, Incorporation, and the Nature of Entrepreneurial Risk'. Tech. rep.

J. Heaton \& D. Lucas (2002). 'Capital Structure, Hurdle Rates, and Portfolio ChoiceInteractions in an entrepreneurial firm'. mimeo. 
N. Herranz, et al. (2008). 'The Impact of Owners and Policy on Small Firms' .

T. Hintermaier \& W. Koeniger (2011). 'Bankruptcy and Debt Portfolios'. CEPR Discussion Paper 8359:1-53.

Y. Jia (2010). 'The Impact of Personal Bankruptcy Law on Entrepreneurship' .

N. Kiyotaki \& J. Moore (1997). 'Credit Cycles'. The Journal of Political Economy 105(2):211248.

R. M. Lawless \& E. Warren (2005). 'The Myth of the Disappearing Business Bankruptcy'. California Law Review 93(3):745-795.

W. Li \& P.-D. Sarte (2006). 'U.S. Consumer Bankruptcy Choice: The Importance of General Equilibrium Effects'. Journal of Monetary Economics 53(3):613-631.

I. Livshits, et al. (2007). 'Consumer Bankruptcy: A Fresh Start'. American Economic Review 97(1):402-418.

X. Mateos-Planas \& G. Seccia (2006). 'Welfare Implications of Endogenous Credit Limits with Bankruptcy'. Journal of Economic Dynamics and Control 30(11):2081-2115.

E. McGrattan \& E. Prescott (2001). 'Is the Stock Market Overvalued?'. Tech. rep., National Bureau of Economic Research.

C. Meh \& Y. Terajima (2008). 'Unsecured Debt, Consumer Bankruptcy, and Small Business'. mimeo.

M. Pavan (2008). 'Consumer Durables and Risky Borrowing: The Effects of Bankruptcy Protection'. Journal of Monetary Economics 55(8):1441-1456.

V. Quadrini (2000). 'Entrepreneurship, Saving, and Social Mobility'. Review of Economic Dynamics 3(1):1-40.

G. Solon (1992). 'Intergenerational income inequality in the United States'. American Economic Review 82(3):393-408.

K. Storesletten, et al. (2001). 'How Important Are Idiosyncratic Shocks? Evidence from Labor Supply'. The American Economic Review 91(2):413-417.

K. Storesletten, et al. (2004). 'Consumption and Risk Sharing Over the Life Cycle'. Journal of Monetary Economics 51(3):609-633. 
G. Tauchen (1986). 'Finite State Markov Chain Approximations to Univariate and Vector Autoregressions'. Economics Letters 20:177-181.

G. Vereshchagina \& H. Hopenhayn (2009). 'Risk Taking by Entrepreneurs'. The American Economic Review 99(5):1808-1830.

M. White (2007). 'Bankruptcy Law'. In A. M. Polinsky \& S. Shavell (eds.), Handbook of Law and Economics, vol. 2. Elsevier. 